JGR Oceans

\author{
RESEARCH ARTICLE \\ 10.1029/2020JC016115 \\ Key Points: \\ - The vertical biogeochemical \\ structure of Southern Ocean \\ cold-core eddies is characterized \\ from observations \\ - Below the mixed layer, eddy \\ dynamics determined nutrient \\ distribution and biological processes \\ above the mixed layer \\ - Long-lived cold-core eddies carry \\ high nitrate and low silicate across \\ the Subantarctic Front south of \\ Tasmania
}

Supporting Information:

- Supporting Information S1

Correspondence to:

R. S. Patel,

Ramkrushnbhai.Patel@utas.edu.au

Citation:

Patel, R. S., Llort, J., Strutton, P. G., Phillips, H. E., Moreau, S.

Conde Pardo, P., \& Lenton, A. (2020).

The biogeochemical structure of Southern Ocean mesoscale eddies. Journal of Geophysical Research:

Oceans, 125, e2020JC016115. https:// doi.org/10.1029/2020JC016115

Received 29 JAN 2020 Accepted 18 JUN 2020 Accepted article online 21 JUN 2020

(C)2020. American Geophysical Union. All Rights Reserved.

\section{The Biogeochemical Structure of Southern Ocean Mesoscale Eddies}

\author{
Ramkrushnbhai S. Patel ${ }^{1,2}$ D , Joan Llort ${ }^{1,3}$ (D), Peter G. Strutton ${ }^{1,4}$ (D), Helen E. Phillips ${ }^{1,4}$ (D, \\ Sebastien Moreau ${ }^{1,5,6}$ (D) Paula Conde Pardo ${ }^{7,8}$, and Andrew Lenton ${ }^{8,9,10}$ (iD \\ ${ }^{1}$ Institute for Marine and Antarctic Studies (IMAS), University of Tasmania (UTas), Hobart, Tasmania, Australia, \\ ${ }^{2}$ Australian Research Council Centre of Excellence for Climate System Science, University of Tasmania, Hobart, \\ Tasmania, Australia, ${ }^{3}$ Barcelona Supercomputing Center, Barcelona, Spain, ${ }^{4}$ Australian Research Council centre of \\ Excellence for Climate Extremes, University of Tasmania, Hobart, Tasmania, Australia, ${ }^{5}$ Norwegian Polar Institute, Fram \\ Center, Tromsø, Norway, ${ }^{6}$ Australian Research Council Antarctic Gateway Partnership, University of Tasmania, Hobart, \\ Tasmania, Australia, ${ }^{7}$ Antarctic Climate and Ecosystems Cooperative Research Centre, University of Tasmania, Hobart, \\ Tasmania, Australia, ${ }^{8}$ Commonwealth Scientific and Industrial Research Organisation (CSIRO) Oceans and Atmosphere, \\ Castray Esplanade, Hobart, Tasmania, Australia, ${ }^{9}$ Centre for Southern Hemisphere Oceans Research, CSIRO, Castray \\ Esplanade, Hobart, Tasmania, Australia, ${ }^{10}$ Australian Antarctic Program Partnership, IMAS-UTas, Hobart, Tasmania, \\ Australia
}

Abstract Mesoscale eddies play a key role in modulating physical and biogeochemical properties across the global ocean. They also play a central role in cross-frontal transport of heat, freshwater, and carbon, especially in the Southern Ocean. However, the role that eddies play in the biogeochemical cycles is not yet well constrained, partly due to a lack of observations below the surface. Here, we use hydrographic data from two voyages, conducted in the austral summer and autumn, to document the vertical biogeochemical structure of two mesoscale cyclonic eddies and quantify the role of these eddies in the meridional transport of nutrients across the Subantarctic Front. Our study demonstrates that the nutrient distribution is largely driven by eddy dynamics, yielding identical eddy structure below the mixed layer in both seasons. This result allowed us to relate nutrient content to dynamic height and estimate the average transport by eddies across the Subantarctic Front. We found that relative to Subantarctic Zone waters, long-lived cold-core eddies carry nitrate anomalies of $1.6 \pm 0.2 \times 10^{10}$ moles and silicate anomalies of $-5.5 \pm 0.7 \times 10^{10}$ moles across the fronts each year. This cross-frontal transport of nutrients has negligible impact on Subantarctic Zone productivity; however, it has potential to modify the nutrient content of mode waters that are exported from the Southern Ocean to lower latitudes.

Plain Language Summary Mesoscale eddies are rotating bodies of water with diameters between 30 and $300 \mathrm{~km}$ that span weeks to months in the ocean. They are known to carry macronutrients (i.e., nitrate, silicate, and phosphate) across the Antarctic Circumpolar Current. Because of extremely limited direct observations of these eddies, it is difficult to calculate the actual quantity of nutrients that these eddies carry. Here we present new observations of two cold-core eddies that we sampled during austral summer and austral autumn in the Southern Ocean south of Tasmania. We found that both eddies had similar nutrient distribution over their depth, especially below the mixed layer depth. Hence, this result motivated us to combine our observation with satellite observation to calculate the quantity of nutrients carried into the Subantarctic Zone by all the similar eddies. We found that eddies carried high-nitrate and low-silicate waters into the Subantarctic Zone. This transport has negligible impact on local biological production, but it has the capacity to change the nutrient content of waters that are exported from the Southern Ocean to lower latitudes.

\section{Introduction}

Oceanic mesoscale eddies (diameter of 30-300 km and lifespan of weeks to months) are ubiquitous. Their dynamical properties, such as rotational speed, amplitude, and diameter, and physical structure are well documented for the Southern Ocean (Frenger et al., 2015; Joyce et al., 1981; Patel et al., 2019; Swart et al., 2008). Mesoscale eddies (hereafter referred to simply as eddies) have been shown to be an important mechanism for transporting heat, freshwater, and carbon across the Antarctic Circumpolar Current 
(ACC Dufour et al., 2015; Ito et al., 2010; Moreau et al., 2017; Patel et al., 2019). They are also likely to be an important mechanism for the cross-frontal transport of macronutrients (i.e., nitrate, phosphate, and silicate; hereafter referred to simply as nutrients), thereby tempering the strong meridional and seasonal gradients of Southern Ocean frontal systems (Ardyna et al., 2017; Pollard et al., 2002, 2006). While we have a relatively good understanding of the physical structure of eddies and their role in meridional transports, we have a limited understanding of the biogeochemical structure of eddies and their role in nutrient transport. This is due to limited hydrographical observations, challenging sampling conditions and the ephemeral nature of eddies. These factors limit both our understanding of the impact of Southern Ocean eddies on global nutrients supply and our capacity to simulate eddy-driven biogeochemical processes.

It is well known that the Southern Ocean supplies nutrients to lower latitudes via Subantarctic Mode Water (SAMW) formation, subduction, and export and plays a central role in modulating global biogeochemical cycles (Hauck et al., 2018; Palter et al., 2010; Rintoul, 2018; Sarmiento et al., 2004). Furthermore, it has been observed that SAMW is high in nitrate and low in silicate especially where SAMW waters form (Demuynck et al., 2019; Sarmiento et al., 2004). However, the mechanisms contributing to this nitrate enrichment and silicate depletion in the SAMW content are yet not well quantified. In this sense, Demuynck et al. (2019) have recently proposed that the meridional gradient of silicate at the surface layer is regulated by the physical processes that connect the deep ocean to the surface layer rather than biological processes. However, due to limitations of the model used in Demuynck et al. (2019), the authors could not quantify the role of eddies and the Ekman transport in redistributing nutrients, which are crucial for transporting tracers meridionally across the ACC and setting the meridional gradients (Dufour et al., 2015; Ito et al., 2010; Palter et al., 2013). The lack of understanding of the biogeochemical 3D structure of eddies and their role in nutrient transport limits a complete evaluation of the impact of mesoscale circulation on both carbon cycle and nutrient supply to lower latitudes.

In this study, we present new in situ observations that shed light on both the vertical structure of biogeochemical properties inside eddies and the ability of eddies to transport nutrients across the ACC. The observations were collected in austral summer and autumn, allowing consideration of the seasonal difference. Our observations are from the Australian sector of the Southern Ocean which is a hotspot for mesoscale activity. In this region, the interaction of the ACC with the Southeast Indian Ridge creates instabilities in the ACC's fronts, which in turn generates eddies (Morrow et al., 2004; Spall, 2000). We particularly focus on cyclonic eddies generated by instability of the SAF (Morrow et al., 2004). These cyclonic eddies can either dissipate in the Subantarctic Zone (SAZ) or in the SAF (Patel et al., 2019). The pathways that these eddies take after spawning are critical to understanding the role of eddies in the meridional transport of physical and biogeochemical properties.

Several regional studies have highlighted that the way eddies alter ocean biology and biogeochemistry depends strongly on the local environment and mechanisms at play (Chenillat et al., 2016; Gruber et al., 2011; Kahru et al., 2007; Kuwahara et al., 2008; Nencioli et al., 2008). There are four dominant mechanisms by which eddies influence the local environment: eddy pumping, eddy-Ekman pumping, eddy advection, and eddy trapping (Frenger et al., 2018; Siegel et al., 2011). Among these four mechanisms, we will focus on eddy pumping (vertical movement of isopycnals caused by eddy dynamics) and eddy trapping. The former is a commonly observed mechanism with potentially large impact on ocean productivity, and the latter is the predominant mechanism for transport of discrete bodies of water across ocean basins or fronts, or both. In nutrient-deficient water, eddy pumping can inject nutrient-rich subsurface waters into the photic zone by vertical uplift of isopycnals, resulting in enhancement of primary production (Falkowski et al., 1991). On the other hand, eddy trapping can reduce primary production locally by transporting nutrient-replete waters and productive ecosystems into oligotrophic regions (e.g., as shown to occur in upwelling systems by Chenillat et al., 2016; Gruber et al., 2011). Thus, it is critical to observe and define these local characteristics, to fully understand the influence of eddies over ocean biogeochemical cycles and climate.

The following are the central questions addressed in this paper. (1) What is the biogeochemical structure of mesoscale cyclonic eddies in the Southern Ocean? (2) What is their contribution to cross-frontal transport of nutrients? (3) How does this nutrient transport impact the local environment? We first characterize the vertical biogeochemical structure of two cold-core eddies, using in situ observations from one voyage in austral 

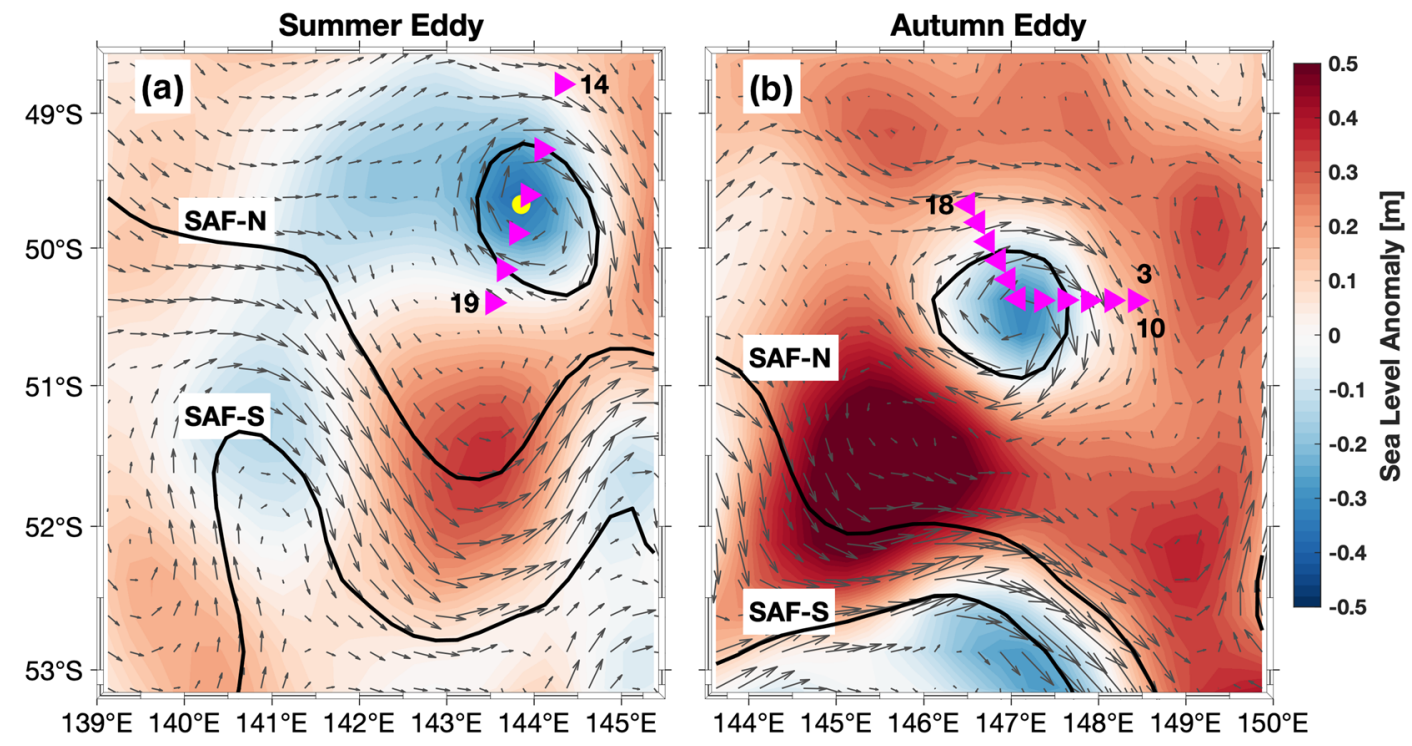

Figure 1. Sampling locations for the cyclonic eddies. Left (a): stations occupied during IN2018_V01, the summer voyage. Right (b): stations occupied during IN2016_V02, the autumn voyage. Magenta triangles denote CTD stations. Black contours represent the northern and southern branch of the Subantarctic Front (SAF-N and SAF-S, respectively) calculated from absolute dynamic height following Sokolov and Rintoul (2009). Color shading represents sea-level anomaly. Arrows represent geostrophic velocity calculated from mean absolute dynamic height. Yellow dot represents altimetry-derived center position of the summer eddy.

summer and another in austral autumn. We then quantify nutrient transport into the SAZ by combining our observations with the history of satellite sea surface height observations in the region. Finally, we discuss the impact of this transport on the modification of SAMW properties and SAZ productivity.

\section{Data and Methods}

\subsection{Shipboard Observational Data Sets}

Two research voyages were conducted in the Southern Ocean south of Tasmania on Australia's $R V$ Investigator. We refer to these voyages as autumn (IN2016_V02) and summer (IN2018_V01) voyage. The in situ observations from these two voyages were combined to provide insight into seasonal differences in vertical biogeochemical structure.

\subsubsection{Autumn Voyage}

This voyage was a dedicated eddy sampling voyage to understand the biological and physical structure of Southern Ocean eddies and their role in carbon cycling. A detailed survey of a cold-core, cyclonic eddy was conducted from 30 March to 5 April 2016. Three radial transects through the eddy were accomplished, as described in Patel et al. (2019) and shown here in Figure 1a. Conductivity-temperature-depth (CTD) casts at 18 stations gave profiles of temperature, salinity, oxygen, backscattering, and fluorescence, and water samples were taken to measure chlorophyll, particulate organic carbon, and nutrients (including ammonium). A Seabird CTD system within a rosette of 36 12-L Niskin bottles was used. This sampled eddy was formed in the SAF south of Tasmania and contained SAF water masses in its core. Its life history from formation, excursion into the SAZ, decay, and finally return to the SAF and dissipation is described in Patel et al. (2019). Hereafter, we refer to this eddy as the autumn eddy.

\subsubsection{Summer Voyage}

The GO-SHIP repeat hydrographic survey was conducted in January 2018 along the WOCE SR03 section between Tasmania and Antarctica. These repeated sections occasionally encounter eddies, due to high eddy activity in the SAZ south of Tasmania (Herraiz-Borreguero \& Rintoul, 2010), and on this voyage, the section traversed a cold-core eddy on 17-18 January 2018 (as shown in Figure 2). Six CTD stations from this voyage were used to construct a transect of physical (temperature and salinity) and biogeochemical parameters (chlorophyll, oxygen, and nutrients including ammonium), four within the eddy and one each on the 

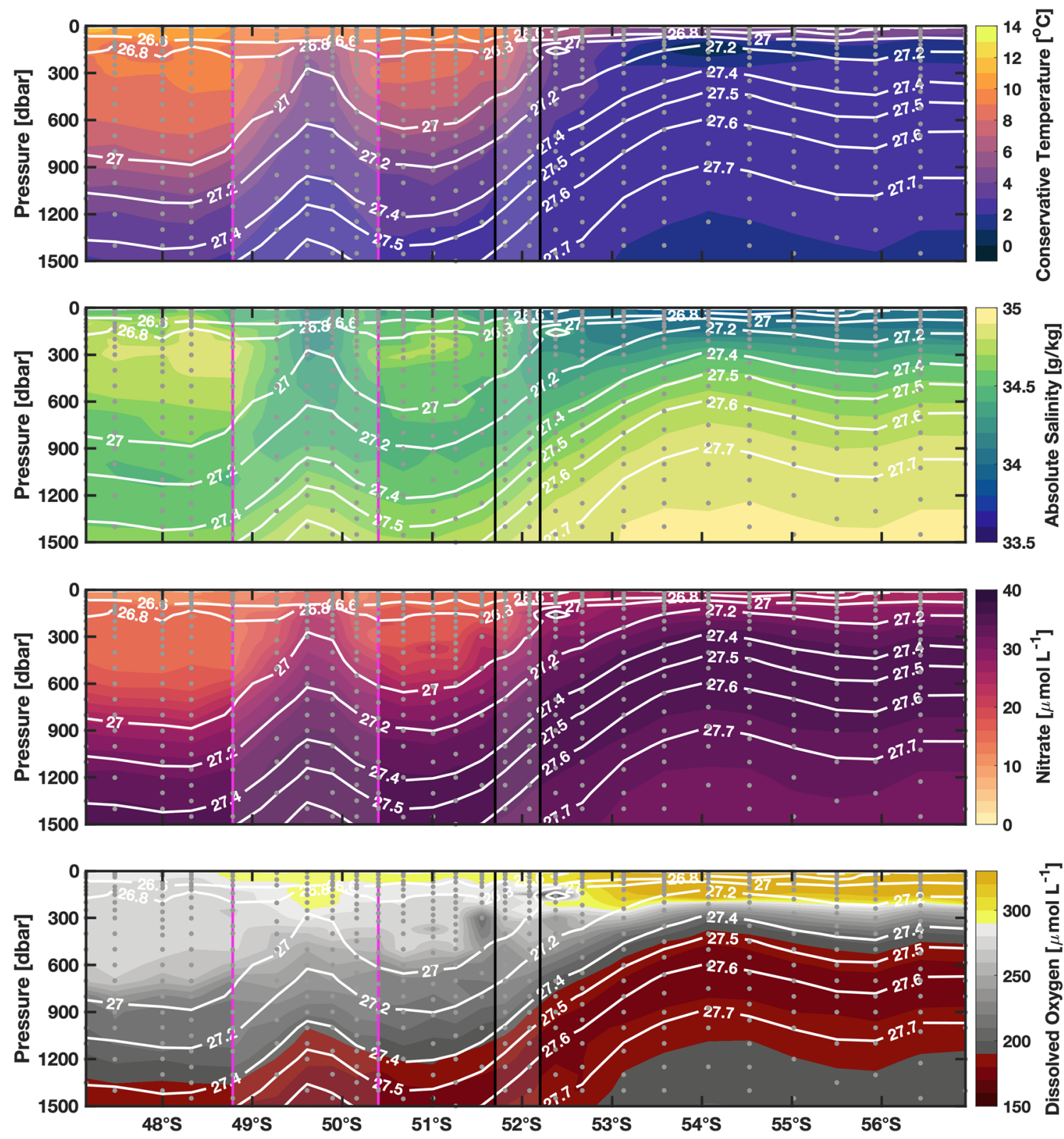

Figure 2. Vertical distribution of conservative temperature, absolute salinity, nitrate, and dissolved oxygen overlaying potential density contours along the WOCE SR03 line in January 2018 (IN2018_V01). Region delimited by magenta lines indicates the location of the summer eddy. Vertical black lines indicate the location of the Subantarctic Front where the eddy was formed in October prior to this voyage. Dots denote bottle sample locations.

northern and southern side of the eddy. The stations are arranged as a transect from the north-eastern to south-western edge of the eddy (Figure 1b). A Seabird CTD system with a rosette of 36 10-L Niskin bottles was used on this voyage. This eddy was formed in the SAF south of Tasmania, further west than the autumn eddy (Figure 1). Hereafter, we refer to this eddy as the summer eddy. The meridional sections of properties measured along the SR03 transect illustrated that the density structure and water properties in the summer eddy core (magenta vertical lines) reflect those at the SAF where the eddy was believed to originate (black vertical lines, Figure 2).

\subsection{Water Sample Analysis}

During both voyages, nutrient samples were analyzed using similar methods and instruments, as described in Moreau et al. (2017). The concentrations of nutrients were determined with a Seal AA3 segmented flow instrument based on methods described by Wood et al. (1967) and Armstrong et al. (1967). The precision 
for reactive silicate was $\pm 0.2 \mu \mathrm{mol} \mathrm{L} \mathrm{L}^{-1}$ and for other nutrients, $\pm 0.02 \mu \mathrm{mol} \mathrm{L}{ }^{-1}$. Salinity and dissolved oxygen samples were analyzed using an Autosal laboratory salinometer and photometric oxygen system, respectively. Further details of the calibrations are available in the data processing reports (https://www.cmar. csiro.au/data/trawler/index.cfm).

\subsubsection{Chlorophyll}

Chlorophyll concentration is used as a proxy for phytoplankton biomass. Chlorophyll was measured at five discrete depths, from the surface to $200 \mathrm{dbar}$, including the subsurface maximum in fluorescence, if present. Further details on bottle extraction of chlorophyll for the autumn voyage are provided in Moreau et al. (2017).

The voltage from the fluorometer mounted on the CTD rosette was converted to chlorophyll concentrations $\left(\mu \mathrm{g} \mathrm{L}^{-1}\right)$ via regression analyses with colocated extracted chlorophyll measurements. Regression analyses were significant for both the summer (slope $=0.18, R^{2}=0.52, N=83$ ) and the autumn (slope $=0.14, R^{2}=0.75$, $N=139$ ) eddies as shown in supporting information, Figure $\mathrm{S} 1$. The units for the slope were $\mu \mathrm{g} \mathrm{L}^{-1} / \mathrm{raw}$ fluorescence units. The raw fluorescence units for the summer eddy were $\mu \mathrm{g} \mathrm{L}{ }^{-1}$ so the slope is dimensionless, and for the autumn eddy, the units were volts. Fluorescence profiles were corrected for quenching using the Sackmann et al. (2008) methodology before the regression analysis (Grenier et al., 2015).

\subsubsection{Particulate Organic Carbon}

Particulate organic carbon (POC) is composed of autotrophic and heterotrophic microorganisms and biologically produced detritus. It is also an indicator of the zooplankton food source (Wang et al., 2011). We collected seawater samples of $1,055 \mathrm{ml}$ from Niskin bottles at three depths on 11 stations to measure POC on the autumn eddy voyage. Precombusted $\left(450^{\circ} \mathrm{C}\right.$ for $\left.12 \mathrm{~h}\right), 25-\mathrm{mm}$ sized GF/F filters were used to filter the collected water samples. Filters were then placed in individual sterile glass vials and wrapped in aluminum foil to curtail light exposure. The filters were stored at $-20^{\circ} \mathrm{C}$ until they were analyzed at Central Science Laboratory, University of Tasmania. A Thermo Finnigan EA 1112 Series Flash Elemental Analyzer was used for measuring POC at a precision of $\sim 1 \%$. Standard carbon-hydrogen-nitrogen combustion methods were used to determine POC.

To assess POC distribution across both eddies, we estimated POC from beam attenuation $\left(C_{p}\right)$. Following Strutton et al. (2011), we computed $C_{p}$ as $C_{p}=-\ln (\operatorname{Tr}) / x\left(\mathrm{~m}^{-1}\right)$, where $x$ is the instrument path length $(0.25 \mathrm{~m})$ and $\mathrm{Tr}$ is transmittance (\%) measured by a C-Star transmissometer mounted on the CTD rosette. Then, we derived the linear relationship between POC measured in the autumn eddy and $C p$ : POC $\left(\mu \mathrm{g} \mathrm{L} \mathrm{L}^{-1}\right)=10.9+373 C p$ with a correlation, $r=0.93, N=32$. The slope of the relationship was $31.08 \mathrm{mmol}$ $\mathrm{m}^{-2}$, which compares well with Strutton et al. (2011) who found $34.96 \mathrm{mmol} \mathrm{m}^{-2}$. It is important to note that we did not filter spikes from the transmittance data, as positive spikes indicate aggregation of particles (Briggs et al., 2011). We applied the same relationship to the summer eddy because POC was not analyzed during that voyage, but the same C-Star transmissometer was used. A drift in the accuracy of the transmissometer might be a source of error in the present study.

\subsection{Definition of Anomaly}

The vertical nutrient structure of eddies was determined as an anomaly from the surrounding SAZ environment. The nutrient anomalies were computed using both isobaric (pressure) and isopycnal (density) as vertical coordinates. The isobaric reference frame is commonly used to illustrate anomalies in the study of eddies (e.g., Kuwahara et al., 2008; Morrow et al., 2004; Nencioli et al., 2008; Swart et al., 2008). However, due to the steep inclination of isopycnals in Southern Ocean eddies, this can confound the interpretation of the anomaly due to the remote source water of the eddy and due to the uplift or depression of water masses by eddy dynamics. The isopycnal reference frame clearly separates these two effects.

To determine nutrient anomalies, we follow the approach used by Patel et al. (2019) to define heat and salt content anomalies in the autumn eddy. In this approach, CTD stations at the extremity of the eddy were averaged to construct a reference profile, in both isobaric and iospycnal coordinates. Then, the reference profile was subtracted from each station. For isopycnal coordinates, we first interpolated bottle-sampled data onto a uniform grid of potential density relative to the sea surface, with a grid spacing of $0.02 \mathrm{~kg} \mathrm{~m}^{-3}$. Potential density was calculated from conservative temperature and absolute salinity using the GSW package (McDougall \& Barker, 2011). 
The reference profile for the summer eddy is the average of Stations 14 and 19 and for the autumn eddy is the average of Stations 3, 10, and 18 (Figure 1). The choice of reference stations was based on two criteria: (1) profiles had water properties characteristic of the SAZ (local environment) based on examination of Theta-S diagram and (2) the stations were located outside the outermost closed contour of the relative vorticity, computed from satellite-measured geostrophic surface currents, as described in Patel et al. (2019).

\subsection{AN Content Anomaly}

The available nutrient (AN) content anomaly is defined as the quantity of nutrients contained between two isopycnals per unit distance along a transect minus the same quantity computed in the reference profile. It represents the nutrient content that is retained in the eddy even after all density surfaces are flattened (Joyce et al., 1981). This method allows us to estimate how much nutrient these eddies can relocate permanently due to mixing and water mass modification along isopycnals as they migrate. We refer to available nutrient content anomalies as ANs.

We estimate the quantity of nutrients carried by the eddies using the approach of Ladd et al. (2007). The authors have adapted this method from Joyce et al. (1981) who initially used it for estimating available heat and salt content anomalies in eddies. Nitrate, silicate, and phosphate profiles were first interpolated onto potential density relative to the the sea surface, with an interval of $0.02 \mathrm{~kg} \mathrm{~m}^{-3}$. The reference profile for each was constructed on the same potential density grid. A profile of available nutrients $\left(\mathrm{mol} \mathrm{m}^{-2}\right)$ was then calculated between isopycnal layers $\sigma_{i}$ and $\sigma_{i-1}$ based on the difference between each profile within the eddy and the reference profile of that eddy at the interval of $0.1 \mathrm{~kg} \mathrm{~m}^{-3}$ as

$$
A N_{\sigma_{i}}=1000 h_{i}\left[N_{\sigma_{i}}-N_{\sigma_{i}}(r e f)\right]
$$

where $h_{i}$ is the thickness of each $0.1 \mathrm{~kg} \mathrm{~m}^{-3}$ isopycnal layer in meters; $N_{\sigma_{i}}$ is the averaged nutrient concentration in each isopycnal layer in each profile $\left(\mu \mathrm{mol} \mathrm{L}{ }^{-1}\right)$; and $N_{\sigma_{i}}(r e f)$ is the averaged nutrient concentration in each isopycnal layer for the reference profile $\left(\mu \mathrm{mol} \mathrm{L} \mathrm{L}^{-1}\right)$. The factor of 1,000 converts $\mu \mathrm{mol}$ per liters to $\mu \mathrm{mol}$ per cubic meters. The unit of $A N_{\sigma_{i}}$ is in $\mathrm{mol} \mathrm{m}^{-2}$.

\subsection{Total ANs}

The total AN carried by the eddy (in moles) can be estimated by vertically summing up the AN in each profile $(\Sigma A N)$ and then integrating over the area of the eddy, here approximated as a circle. We limit the vertical summation to the potential density range from 26.5 to $27.5 \mathrm{~kg} \mathrm{~m}^{-3}$. This potential density range encompasses most of the water mass variability evident in Theta-S profiles (Figure S2). Below the upper isopycnal limit $\left(26.5 \mathrm{~kg} \mathrm{~m}^{-3}\right)$, the consumption of nutrients by phytoplankton is negligible, and thus, we regard nutrients as conservative quantities. The deepest isopycnal limit was $27.5 \mathrm{~kg} \mathrm{~m}^{-3}$, where all profiles converged to form a tail-like structure, indicating identical Theta-S properties across all the stations. The potential density range of 26.5 to $27.5 \mathrm{~kg} \mathrm{~m}^{-3}$ corresponds to a depth range from close to the base of the mixed layer $(\sim 100 \mathrm{~m})$ to $\sim 1,000 \mathrm{~m}$ at the center and $\sim 1,400 \mathrm{~m}$ at the edges of the eddies (as shown in Figure 6 of Patel et al., 2019).

The total ANs in the eddy, relative to its surrounding environment is then

$$
\mathcal{N}=\int_{\mathrm{r}=0}^{R} 2 \pi r \cdot \Sigma A N \cdot d r
$$

where $d r$ is the distance between stations, $R$ is the eddy radius, and $\Sigma A N$ is the vertically summed ANs at a station. The unit of $\mathcal{N}$ is in moles.

This formulation treats each CTD profile as representative of the nutrient content of the eddy at the radial position of the CTD relative to the eddy center. Since two radial sections sample the full diameter of each eddy, we calculate $\mathcal{N}$ separately for each radial section to provide an estimate of the variability in $\mathcal{N}$.

\section{Results}

\subsection{Macronutrient Distribution}

Hydrographic sections of dissolved nitrate, silicate, and phosphate across the summer and autumn eddies are presented in Figure 3. These sections capture the pronounced doming of isopycnals and nutrient 

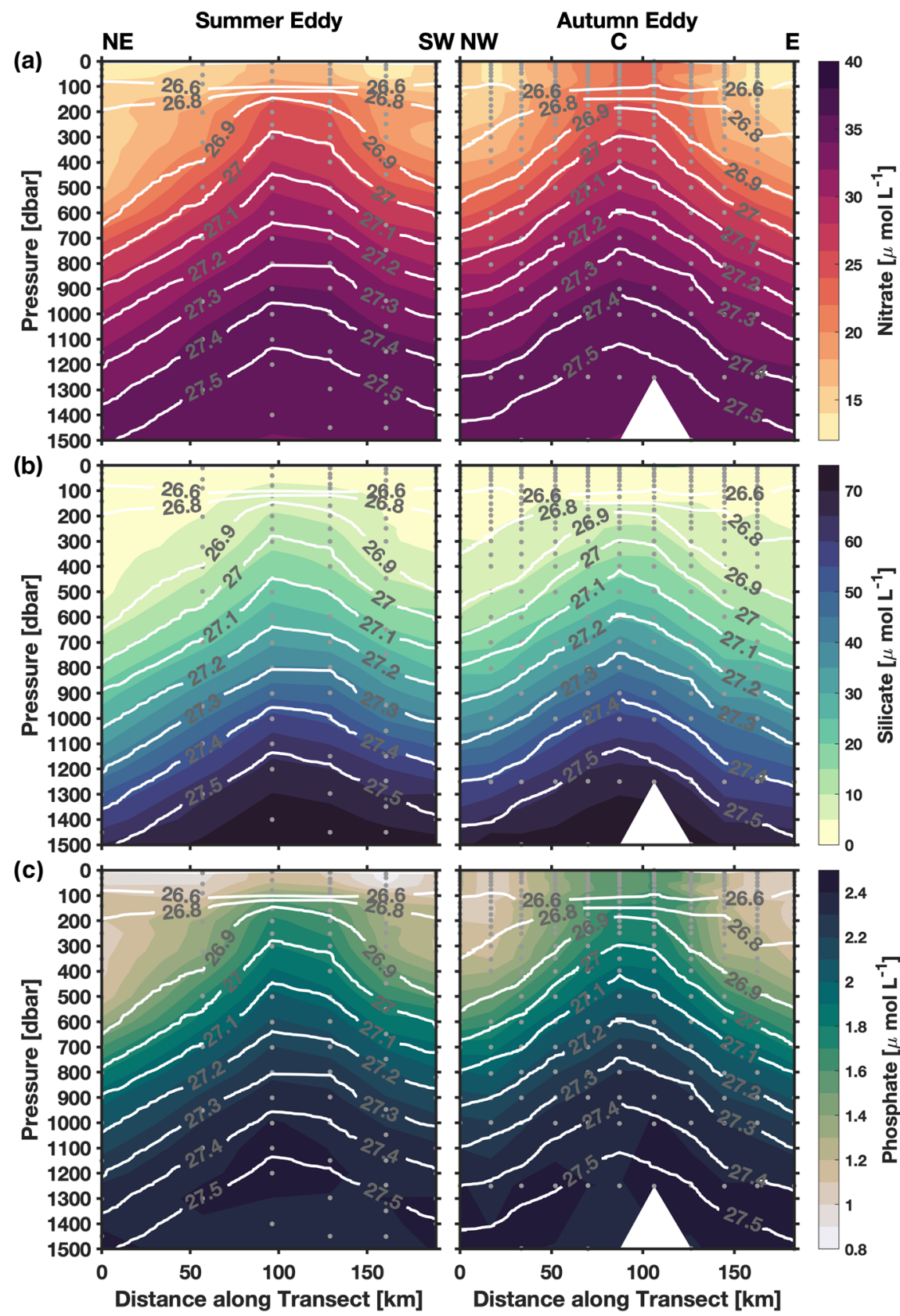

Figure 3. Nutrient (nitrate (a); silicate (b); and phosphate (c)) distribution in the summer eddy (left column) and the autumn eddy (right column). Overlain are the potential density surfaces (minus $1,000 \mathrm{~kg} \mathrm{~m}^{-3}$ ) referenced to the surface. Dots indicate bottle sample depths. The labels on the top axis represent the orientation of the start and end of each transect (summer eddy: northeast (NE) to southwest (SW); autumn eddy: northwest to eddy center to east edge).

isopleths expected in cold-core eddies. Furthermore, the interior distribution of the nutrients is closely aligned with the density surfaces below the mixed layer depth, defined as the $26.6 \mathrm{~kg} \mathrm{~m}^{-3}$ isopycnal. Nitrate isopleths were uplifted from the base of the mixed layer ( $100 \mathrm{dbar})$ to the depth limit of the observations $(\sim 1,500 \mathrm{dbar})$ in the core of both eddies. For example, the nitrate isopleths of $25 \mu \mathrm{mol} \mathrm{L}{ }^{-1}$ shoaled from deeper than $600 \mathrm{dbar}$ at the edge of the eddy to $\sim 200 \mathrm{dbar}$ at the base of the mixed layer in the center of the autumn eddy (Figure 3a). The subsurface structure of phosphate and silicate had similar patterns to nitrate in both eddies. This suggested that the eddy causes the pumping of nutrient-rich waters into shallower layers. Similar distributions have also been observed by Nencioli et al. (2008) and Kuwahara et al. (2008) in Hawaiian island eddies. 


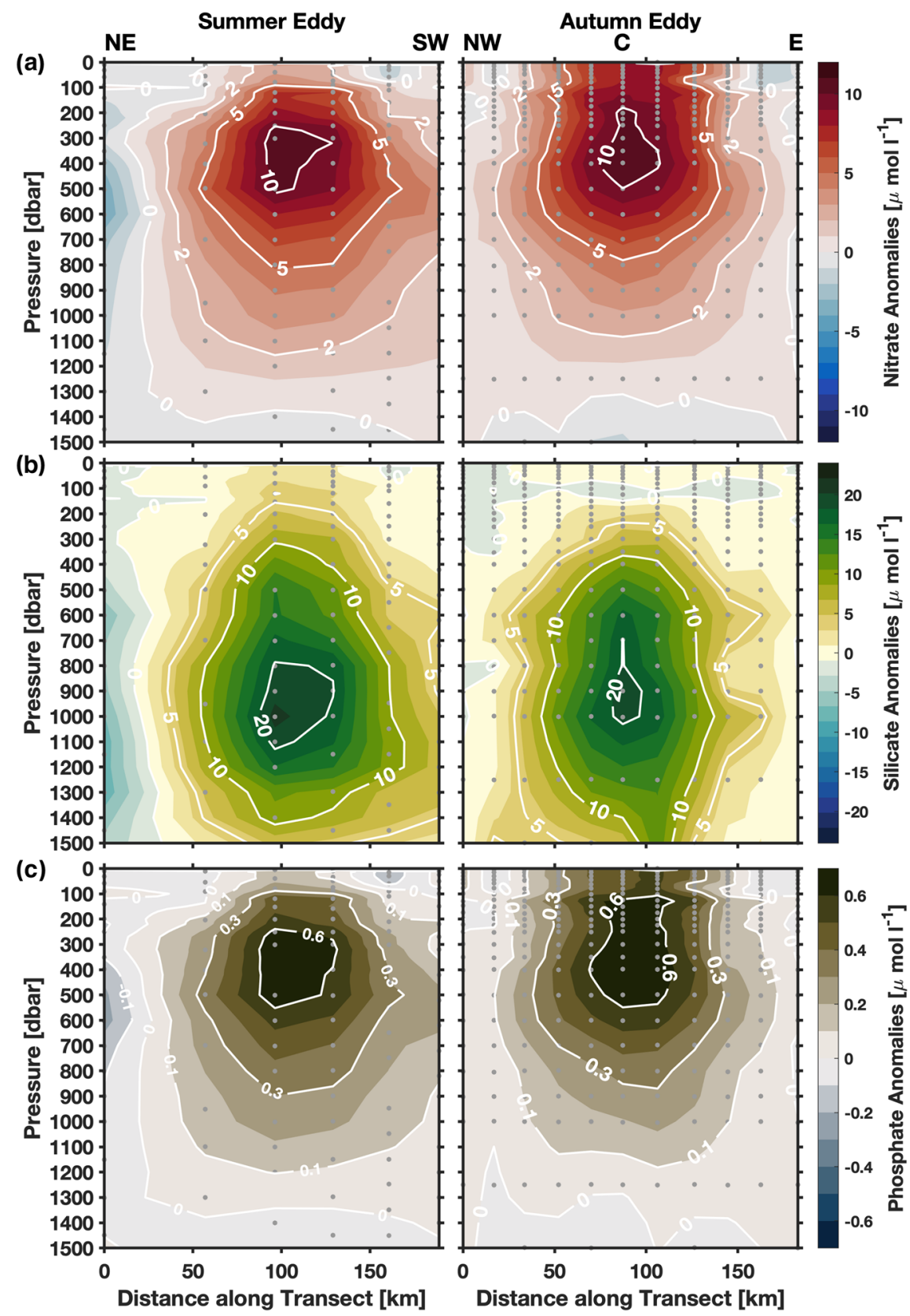

Figure 4. The distribution of nitrate (a), silicate (b), and phosphate (c) anomalies in the summer eddy (left column) and the autumn eddy (right column) referenced to background Subantarctic Zone conditions. The dots indicate bottle sample depths.

In the mixed layer, a strong horizontal gradient in nitrate and phosphate was present, increasing from the edges towards the center, while no apparent gradient of silicate was evident in either eddy (Figure 3). This could be the result of uneven drawdown of nitrate and phosphate, compared with silicate, by biological processes in the mixed layer.

We observed a strong vertical gradient of silicate compared with nitrate in both eddies (Figure 3). Nitrate concentrations ranged from $\sim 18 \mu \mathrm{mol} \mathrm{L}{ }^{-1}$ in the surface mixed layer to $>33 \mu \mathrm{mol} \mathrm{L}^{-1}$ at $1,500 \mathrm{dbar}$ in the summer eddy center and ranged from $\sim 20 \mu \mathrm{mol} \mathrm{L}^{-1}$ in the surface mixed layer to $>33 \mu \mathrm{mol} \mathrm{L} \mathrm{L}^{-1}$ at 1,500 dbar in the autumn eddy center (Figure 3). For both eddies, silicate concentration varied from $<5 \mu \mathrm{mol} \mathrm{L}{ }^{-1}$ in the surface mixed layer to $>70 \mu \mathrm{mol} \mathrm{L}{ }^{-1}$ at $1,500 \mathrm{dbar}$ at the centers. These strong vertical gradients of silicate 
compared with nitrate could indicate a deep source of silicate. Vertical gradients in nutrients were also evident in the CSIRO Atlas of Regional Seas (CARS) climatology (www.cmar.csiro.au/cars) for the region of our eddies.

\subsubsection{Nutrient Anomalies in Cold-Core Eddies}

Anomalies of nitrate, silicate, and phosphate with respect to the SAZ reference profile are presented on isobaric surfaces in Figure 4. Both eddies exhibit positive anomalies of nitrate, silicate, and phosphate compared with surrounding waters. However, the core of silicate anomalies was located deeper than the core of nitrate and phosphate anomalies (Figure 4). In the summer eddy, a nitrate anomaly core of $>10 \mu \mathrm{mol}$ $\mathrm{L}^{-1}$ and a phosphate anomaly core of $>0.6 \mu \mathrm{mol} \mathrm{L}{ }^{-1}$ were concentrated at $\sim 400 \mathrm{dbar}$, whereas a silicate anomaly core of $>20 \mu \mathrm{mol} \mathrm{L}{ }^{-1}$ was concentrated at 1,000 dbar at the eddy center. Likewise, in the autumn eddy, nitrate, silicate, and phosphate anomalies of the same magnitude were concentrated at slightly shallower depths: $\sim 350$ dbar for nitrate and phosphate and 950 dbar for silicate.

The shape of the nitrate anomaly distribution was different in each eddy (Figure 4). The summer eddy had a circular-shaped anomaly centered around a subsurface maximum, whereas the autumn eddy had a bowl-shaped anomaly extending to the sea surface with a subsurface maximum. The nitrate anomaly in the mixed layer at the center of the autumn eddy was about $6 \mu \mathrm{mol} \mathrm{L}{ }^{-1}$ higher than that of the summer eddy. Both eddies had a nitrate anomaly of $\sim 10 \mu \mathrm{mol} \mathrm{L}-1$ in the subsurface maximum near $400 \mathrm{dbar}$. The concentration gradually decreased to zero near 1,300 dbar for both eddies. The phosphate anomaly distribution was similar to that of the nitrate anomaly distribution for both eddies (Figure 4).

The silicate anomaly distribution was approximately similar for both eddies, except in the upper $150 \mathrm{dbar}$ where it was close to zero for the autumn eddy (Figure 4). Both eddies had an elliptical-shaped anomaly with the long axis oriented in the vertical direction, spreading from a subsurface maximum. The maximum silicate anomaly ( $\left.>20 \mu \mathrm{mol} \mathrm{L}{ }^{-1}\right)$ occurred at about 1,000 dbar in both eddies. This deeper location of the anomaly could be due to the uplift of isopycnals in the core of the eddies, and with them the nutrients, and the increase in silicate concentration with depth (Figure 3). At 1,500 dbar, the depth limit of our observations, the isolines of anomalies were not closed, suggesting that we did not capture the full vertical extent of the silicate anomaly.

Anomalies of nitrate, silicate, and phosphate on potential density surfaces between 26.5 and $27.5 \mathrm{~kg} \mathrm{~m}^{-3}$ are shown in Figure 5. This way of presenting the data removes any anomaly seen in isobaric coordinates that is due purely to the uplift or depression of isopycnals. As the eddies decay, the isopycnals relax and it is only the anomaly evident in this isopycnal reference frame that is permanently transported with the eddy.

The nitrate and phosphate anomalies were mainly confined between the surface and $26.95 \mathrm{~kg} \mathrm{~m}^{-3}$ isopycnal in both eddies (Figures 5a and 5c). Above the $26.95 \mathrm{~kg} \mathrm{~m}^{-3}$ isopycnal, both eddies captured positive anomalies of nitrate and phosphate in their cores. Below the $26.95 \mathrm{~kg} \mathrm{~m}^{-3}$ isopycnal, the anomalies were within \pm 1 $\mu \mathrm{mol} \mathrm{L}{ }^{-1}$ for nitrate and $\pm 0.05 \mu \mathrm{mol} \mathrm{L}-1$ for phosphate in both eddies.

However, there was a distinct seasonal difference between the nitrate and phosphate anomaly concentrations (Figures $5 \mathrm{a}$ and $5 \mathrm{c}$ ). In the summer eddy, the maximum nitrate and phosphate anomalies $(>5 \mu \mathrm{mol}$ $\mathrm{L}^{-1}$ and $>0.4 \mu \mathrm{mol} \mathrm{L}{ }^{-1}$, respectively) were found at the center between 26.8 and $26.9 \mathrm{~kg} \mathrm{~m}^{-3}$. In the autumn eddy, the maximum nitrate and phosphate anomalies were higher $\left(>9 \mu \mathrm{mol} \mathrm{L}{ }^{-1}\right.$ and $>0.6 \mu \mathrm{mol} \mathrm{L}{ }^{-1}$, respectively) at the center and at a lighter density, between 26.6 and $26.75 \mathrm{~kg} \mathrm{~m}^{-3}$.

The silicate anomaly in both eddies changed sign near the isopycnal $26.95 \mathrm{~kg} \mathrm{~m}^{-3}$ and the concentration was different between the eddies (Figure $5 \mathrm{~b}$ ). Above the $26.95 \mathrm{~kg} \mathrm{~m}^{-3}$ isopycnal, the summer eddy encapsulated a positive silicate anomaly of $>4 \mu \mathrm{mol} \mathrm{L}{ }^{-1}$ between 26.5 and $26.65 \mathrm{~kg} \mathrm{~m}^{-3}$ and the autumn eddy had no discernible anomaly. Below the $26.95 \mathrm{~kg} \mathrm{~m}^{-3}$ isopycnal, both eddies contained negative anomalies. A tongue of maximum negative silicate anomalies of $-2 \mu \mathrm{mol} \mathrm{L}{ }^{-1}$ extended from the NE edge to the SW edge of the summer eddy. The maximum negative silicate anomalies of about $-5 \mu \mathrm{mol} \mathrm{L}{ }^{-1}$ were concentrated at the center station between 27 and $27.15 \mathrm{~kg} \mathrm{~m}^{-3}$ for the autumn eddy. These results imply that both eddies carried high nitrate and phosphate above $26.95 \mathrm{~kg} \mathrm{~m}^{-3}$ isopycnal and low-silicate water below $26.95 \mathrm{~kg} \mathrm{~m}^{-3}$, from its formation site to the current location. The summer eddy carried high-silicate water above $26.95 \mathrm{~kg} \mathrm{~m}^{-3}$. 

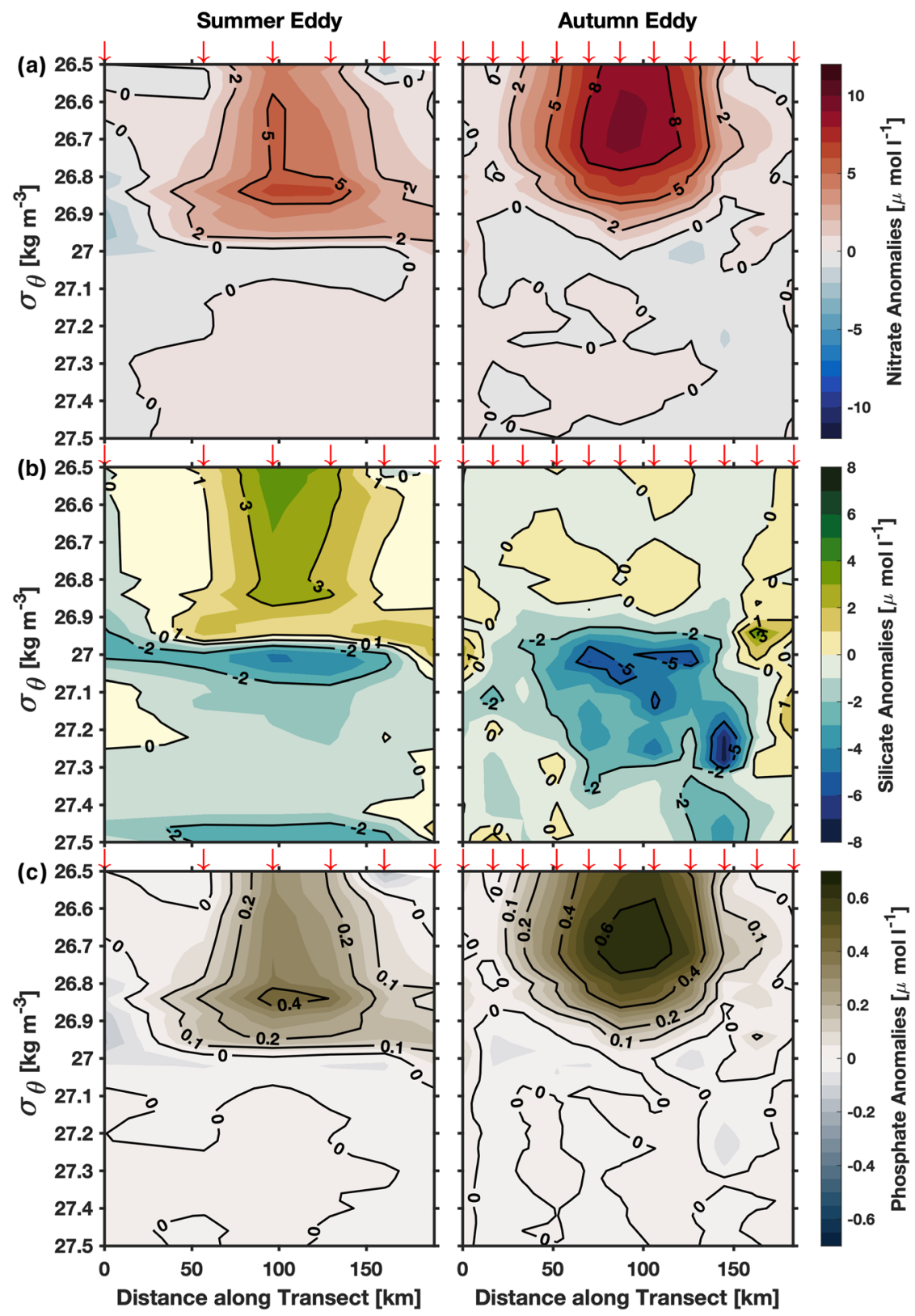

Figure 5. Nitrate (a), silicate (b), and phosphate (c) anomalies in the summer eddy (left column) and the autumn eddy (right column) referenced to Subantarctic Zone, computed along the isopycnal surfaces. Red downward arrows denote CTD stations.

\subsection{Biomass Distribution}

Chlorophyll, estimated from fluorescence, is presented as a proxy for phytoplankton biomass (Figure 6a). Chlorophyll was largely confined to the surface mixed layer in both eddies (above the $26.6 \mathrm{~kg} \mathrm{~m}^{-3}$ isopycnal, Figure $6 a)$. In the summer eddy, chlorophyll was higher in the eddy core than its periphery and was asymmetrically distributed around the eddy core. The chlorophyll concentration decreased from $\sim 0.8 \mu \mathrm{g} \mathrm{L}{ }^{-1}$ at the summer eddy core to $0.5 \mu \mathrm{g} \mathrm{L} \mathrm{L}^{-1}$ at the eddy periphery on the northeastern side and $0.6 \mu \mathrm{g} \mathrm{L}{ }^{-1}$ on the southwestern side. In contrast to the summer eddy, chlorophyll was lower in the autumn eddy core compared with its periphery and was symmetrically distributed around the eddy center. The chlorophyll concentration in the autumn eddy core was between 0.3 and $0.5 \mu \mathrm{g} \mathrm{L} \mathrm{L}^{-1}$ and about $0.6-0.7 \mu \mathrm{g} \mathrm{L}^{-1}$ at its periphery. Below the mixed layer, chlorophyll was homogeneous across the summer eddy, with a concentration 


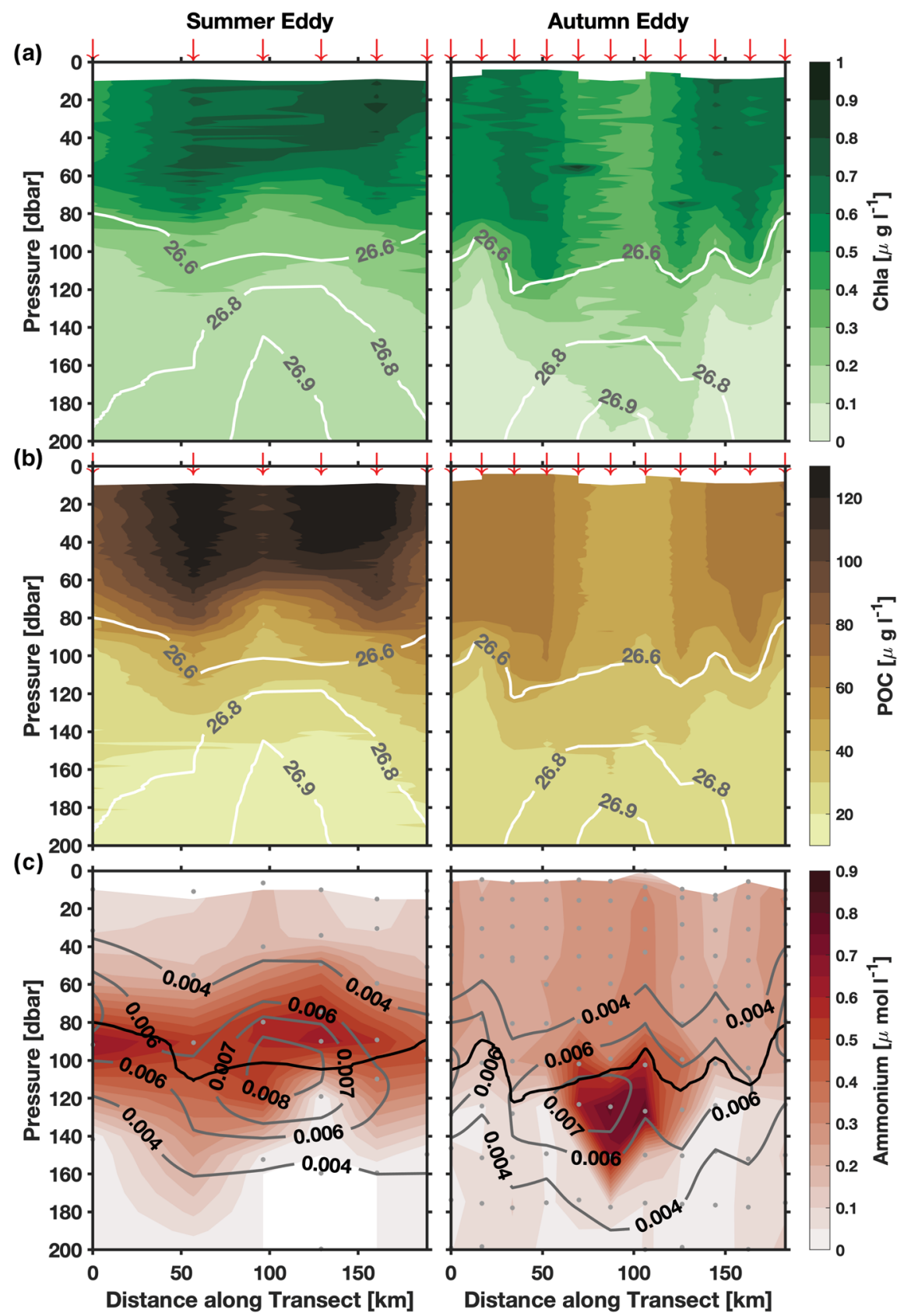

Figure 6. Biological structure associated with the summer and autumn eddy. Chlorophyll (a) presented as proxy for phytoplankton biomass. Particulate organic carbon (b) presented as amalgamated organic matters in the eddies. Ammonium (c) presented as breakdown product of biomass. Potential density surfaces are overlain as white contours (a and b). Brunt-Vaisala frequency $\left(\mathrm{s}^{-1}\right.$ ) overlaid on ammonium as gray contours (c) and the black contour represents mixed layer depth defined by the $26.6 \mathrm{~kg} \mathrm{~m}^{-3}$ isopycnal. Red downward arrows represent station position ( $\mathrm{a}$ and $\mathrm{b}$ ). The dots indicate bottle sample depths (c).

varying between 0.2 and $0.3 \mu \mathrm{g} \mathrm{L} \mathrm{L}^{-1}$ (Figure 6a). In contrast, chlorophyll was heterogeneous across the autumn eddy below the mixed layer (Figure 6a). It was higher in the core $\left(0.1-0.2 \mu \mathrm{g} \mathrm{L}^{-1}\right.$ ) than at the periphery $\left(0-0.1 \mu \mathrm{g} \mathrm{L}^{-1}\right)$.

POC distribution across both eddies corresponded closely to that of chlorophyll (Figure 6b), suggesting a high concentration of autotrophic organisms. In the summer eddy, POC concentration was lower in the core (90-100 $\left.\mathrm{g} \mathrm{L} \mathrm{L}^{-1}\right)$ than in the periphery $\left(>120 \mu \mathrm{g} \mathrm{L}^{-1}\right)$ and symmetrically distributed around the core. 
Likewise, POC concentration in the autumn eddy core was lower (about 50-60 $\mu \mathrm{g} \mathrm{L}{ }^{-1}$ ) than its periphery (about $80 \mu \mathrm{g} \mathrm{L}^{-1}$ ). Only the autumn eddy indicated a ring-shaped distribution in chlorophyll when viewing from the top. The ring shape was also observed in the POC distribution of summer eddy in the upper 60 dbar, but was not clearly evident in chlorophyll (Figures $6 \mathrm{a}$ and $6 \mathrm{~b}$ ). Nonetheless, both POC and chlorophyll distributions indicate that the summer eddy core carried higher concentrations of organic matter than the autumn eddy core, and the autumn eddy exhibited ring-shaped distributions in satellite view, which extends at least up to $26.6 \mathrm{~kg} \mathrm{~m}^{-3}$. Similar types of annular rings of high chlorophyll were previously observed for anticyclones in the Southern Ocean (Kahru et al., 2007). Ours are the first records of the subsurface extent of such a ring in a Southern Ocean cyclonic eddy.

Ammonium is produced as organic matter sinks and is remineralized into inorganic nutrients by bacteria and by zooplankton excretion. This phenomenon is usually associated with a high concentration of biomass. Because phytoplankton prefer ammonium over nitrate for their nitrogen requirements (Wheeler \& Kokkinakis, 1990), ammonium is consumed rapidly, resulting in low concentrations in the surface mixed layer. We observed a relatively high concentration of ammonium $\left(\sim 0.5 \mu \mathrm{mol} \mathrm{L}{ }^{-1}\right)$ around the base of the mixed layer across the summer eddy (Figure 6c). In the autumn eddy, in contrast, ammonium was only concentrated below the mixed layer in the core $\left(>0.7 \mu \mathrm{mol} \mathrm{L}^{-1}\right)$ with lower chlorophyll above.

\subsubsection{Nutrient Stoichiometry and Community Structure}

We observed distinct nutrient stoichiometry between the core and ring portion of the eddies, which suggested that different phytoplankton communities had been growing (Figure 7). The nitrate to phosphate drawdown ratio $(\mathrm{N}: \mathrm{P})$ was lower than or equal to the Redfield ratio (16:1), suggesting that the phytoplankton communities were at least composed in parts by diatoms (Arrigo, 2005; Arrigo et al., 1999). Silicate to nitrate drawdown ratios (Si:N) were very different from the canonical Redfield ratio (1:1) and all indicated significant silicate drawdown; the higher drawdown ratio being associated with more primary production by diatoms and the lower drawdown ratio with more primary production by diatoms compared with other phytoplankton (e.g., flagellates, Takeda, 1998).

In the autumn eddy core, the N:P drawdown was particularly low $(\sim 13)$ and the Si:N drawdown particularly high ( 2). Under iron-limiting conditions for diatoms, such as those occurring south of the Polar Front, Si:N drawdown has previously been observed to be greater than 1. For example, the Si:N drawdown was 8.5 during the SOFEX-S iron amendment mesoscale experiments (Coale et al., 2004). Therefore, both nutrient drawdown ratios in the autumn eddy core are typical of diatom-dominated phytoplankton communities under iron stress. In comparison, the autumn eddy ring represented marginally higher N:P and lower Si: $\mathrm{N}$ drawdown ( $\sim 17$ and 0.4 , respectively). These values are more typical of mixed-phytoplankton communities (Martiny et al., 2013), which are predominant in this time of the year in low-Si subantarctic waters (Hutchins et al., 2001). In the summer eddy core and ring region, both N:P and Si:N drawdown ratios were lower than the Redfield ratios, indicating a significant presence of diatoms under low iron stress.

Silicate concentrations were low in both eddies $\left(<10 \mu \mathrm{mol} \mathrm{L} \mathrm{L}^{-1}\right)$. This reflected the silicon drawdown that takes place in the waters north of the Polar Front and towards the SAF and is responsible for the opal belt, the great sediment accumulation of biogenic silica due to the sinking frustules of heavily silicified diatoms (Smetacek et al., 2004). Second, the apparent increase in nitrate concentration between the summer and autumn eddies is likely due to remineralization (Dehairs et al., 2015).

The $\mathrm{N}^{*}$ and $\mathrm{Si}^{*}$ in both eddies were negative down to at least $300 \mathrm{dbar}$ (Figures $7 \mathrm{c}$ and $7 \mathrm{~d}$ ). The $\mathrm{N}^{*}$ was lower in the autumn eddy than in the summer eddy from the surface to the mixed layer depth, around $80 \mathrm{dbar}$. $\mathrm{N}^{*}$ was particularly low in the core of the autumn eddy, between 100 and $150 \mathrm{dbar}$, where we find high concentration of ammonium (Figure 6c). This could be an indication of recycling of organic material or the presence of zooplankton.

\subsection{AN Distribution}

The ANs in the eddies are the nutrients that can be permanently relocated as the eddy migrates and remain after the eddy decays and isopycnals relax. It is defined by Equation 1 and has units of moles per unit area. Available nitrate, silicate, and phosphate in the summer and autumn eddies are presented in Figure 8. The observations show well-resolved features and capture the full extent of available nitrate and phosphate structure. For the available silicate, the concentration does not go to zero at the deepest 

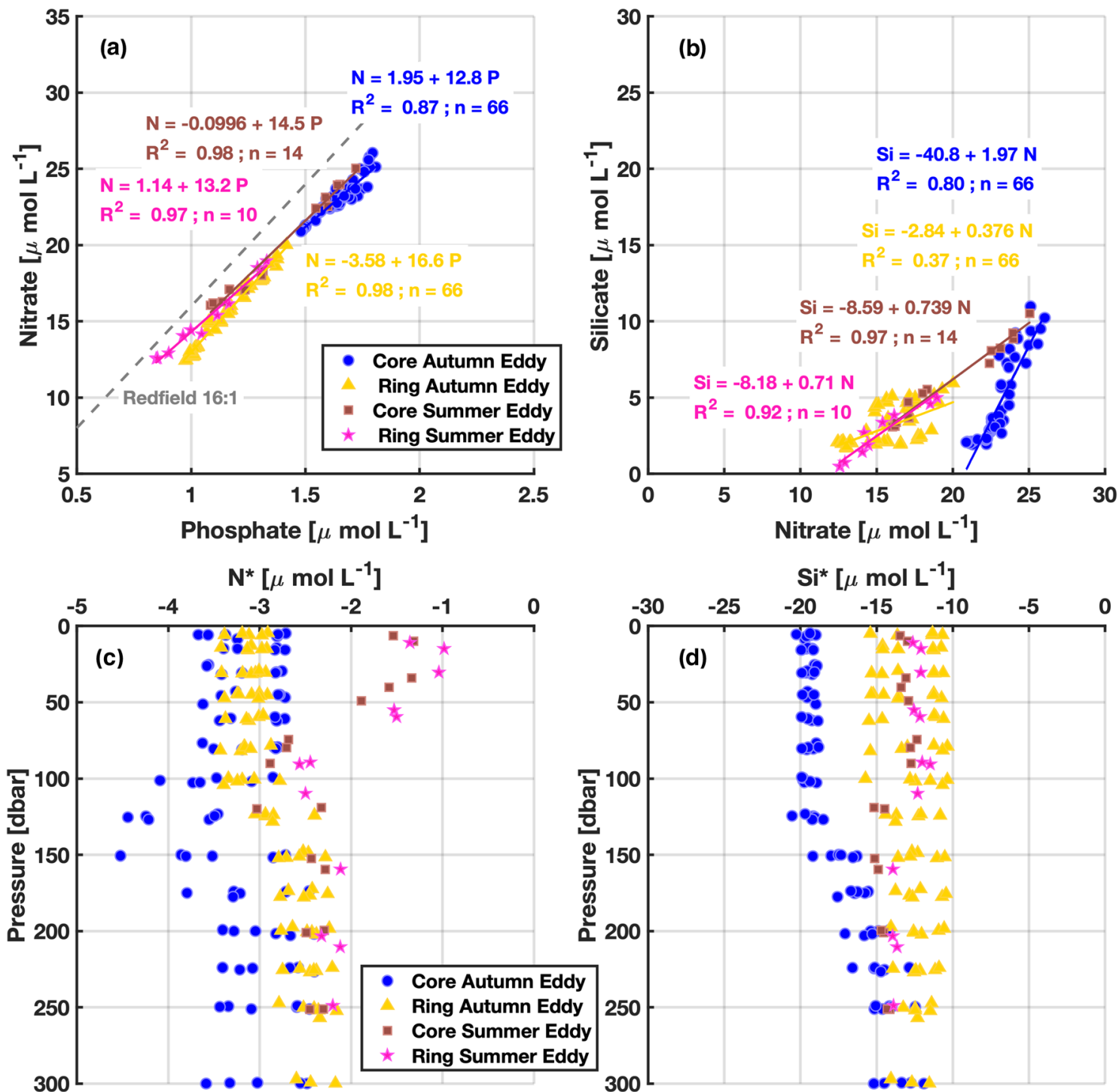

Figure 7. Nutrient stoichiometry across both eddies. Nitrate to phosphate (a) and silicate to nitrate (b) drawdown ratios for the upper 200 dbar in the summer eddy core and ring region and the autumn eddy core and ring region. $\mathrm{N}^{*}(=\mathrm{N}-16 \cdot \mathrm{P}, \mathrm{C})$ and $\mathrm{Si}^{*}(=\mathrm{Si}-\mathrm{N}, \mathrm{D})$ are also presented for the core and ring region of both the eddies for upper 300 dbar.

isopycnal, so it appears that the observations did not capture the full extent of the silicate cell relative to the reference profile. Therefore, our calculations may underestimate the magnitude of silicate anomalies. In the summer eddy, the maximum positive ANs of nitrate $\left(>0.2 \mathrm{~mol} \mathrm{~m}^{-2}\right)$, silicate $\left(>0.1 \mathrm{~mol} \mathrm{~m}^{-2}\right)$, and phosphate $\left(>0.01 \mathrm{~mol} \mathrm{~m}^{-2}\right)$ are concentrated between potential density surfaces 26.8 and $26.95 \mathrm{~kg} \mathrm{~m}^{-3}$ and stronger at the SW edge, giving a sense of a nutrient source at the southwest side of the eddy (right side of Figures $8 \mathrm{a}$ to $8 \mathrm{c}$, left column) penetrating towards the northeast side of the eddy. This is consistent with the high nitrate and phosphate anomalies that were observed in both isobaric and isopycnal coordinates relative to surrounding waters (Figures 4 and 5). This high nutrient signature could have either been captured by the summer eddy core at its origin, or advected into the eddy along isopycnals. We also observed negative AN of nitrate $\left(<-0.2 \mathrm{~mol} \mathrm{~m}^{-2}\right)$, silicate $\left(<-0.1 \mathrm{~mol} \mathrm{~m}^{-2}\right)$, and phosphate $\left(<-0.01 \mathrm{~mol} \mathrm{~m}^{-2}\right)$ in approximately the same density range, 26.8 and $27 \mathrm{~kg} \mathrm{~m}^{-3}$, but near the NE edge of the summer eddy. These negative ANs then appear to be subducted underneath the maximum positive AN of nitrate, silicate, and phosphate. The signal of subduction was distinct in the silicate content structure (Figure 8). 

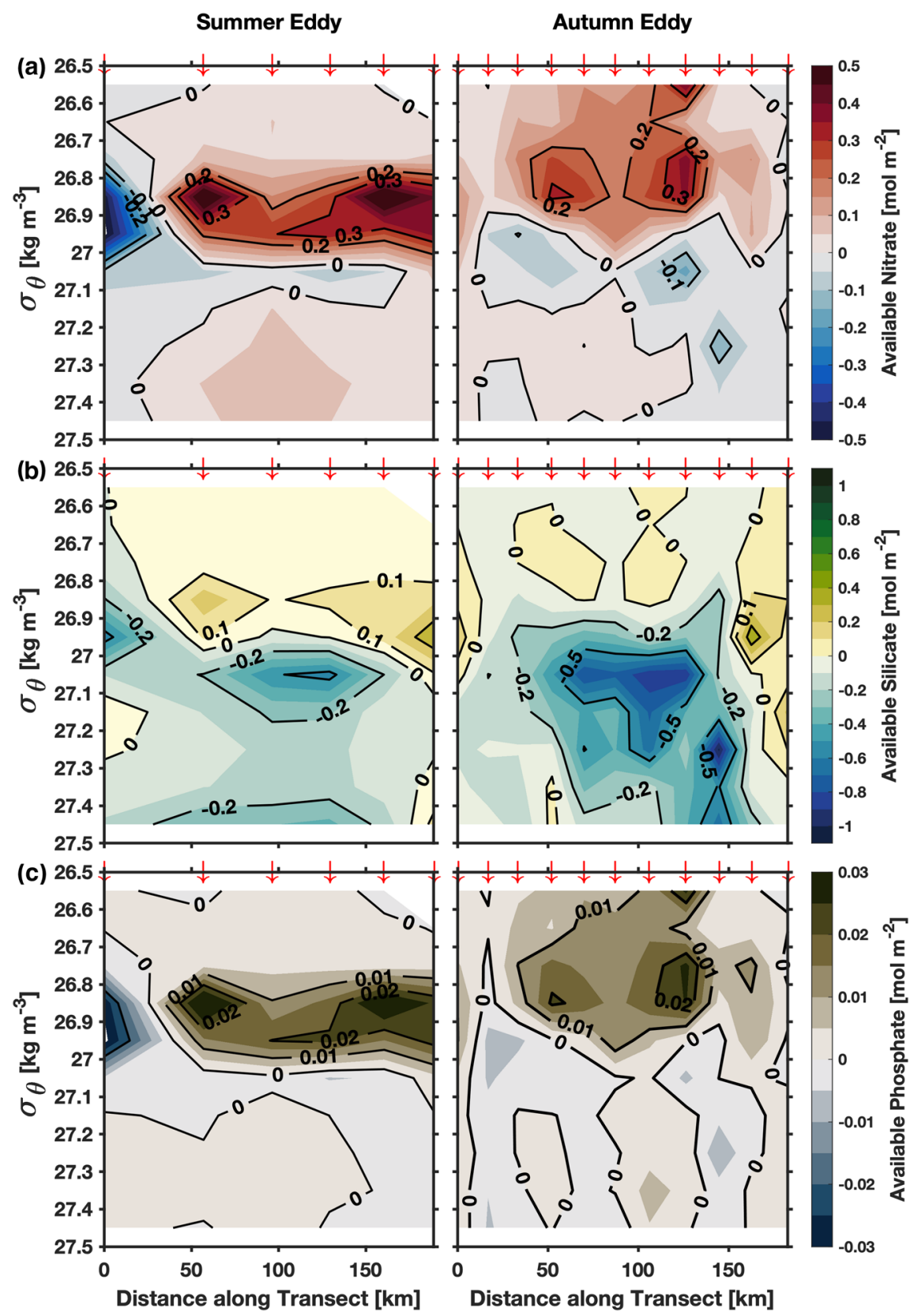

Figure 8. Available nitrate (a), silicate (b), and phosphate (c) in the summer eddy (left column) and the autumn eddy (right column) referenced to the Subantarctic Zone. Red downward arrows represent sampling stations.

In the autumn eddy, two bulges of maximum positive AN of nitrate $\left(>0.2 \mathrm{~mol} \mathrm{~m}^{-2}\right)$ and phosphate $\left(>0.01 \mathrm{~mol} \mathrm{~m}^{-2}\right)$ were located on either side of the eddy center and confined between 26.75 and $26.85 \mathrm{~kg} \mathrm{~m}^{-3}$, indicating symmetry around the eddy center (Figure 8 , left column). Such positive AN was absent in silicate for the autumn eddy. However, the autumn eddy had maximum negative silicate AN of $>-0.5 \mathrm{~mol} \mathrm{~m}^{-2}$ located between 27.05 and $27.25 \mathrm{~kg} \mathrm{~m}^{-3}$, enveloped in slightly positive AN encroaching from the edges of the eddy. Relatively low AN was observed above $26.85 \mathrm{~kg} \mathrm{~m}^{-3}$.

The ANs were next summed vertically from densities of 26.5 to $27.5 \mathrm{~kg} \mathrm{~m}^{-3}$ to understand which part of the eddies contributes the most in the total available nutrients (Figure 9). This analysis indicated that the core region of the eddies carried maximum anomalous nutrients. Furthermore, regardless of the nutrients, the 

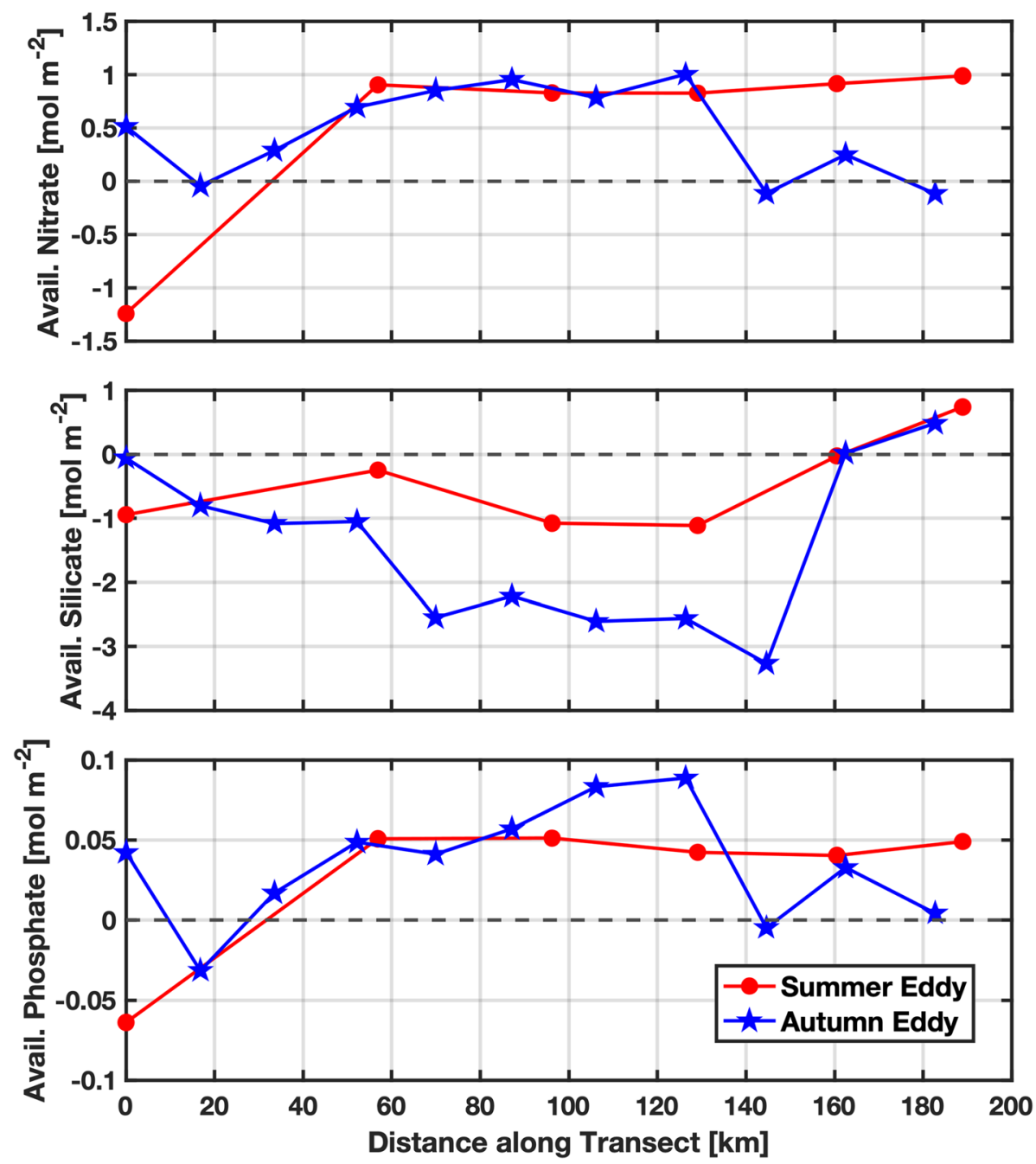

Figure 9. Vertically summed available nitrate (top), silicate (middle), and phosphate (bottom) across the summer eddy and the autumn eddy.

magnitude of AN decreased from the center of an eddy to the edges. This distribution was more distinct in the autumn eddy than the summer eddy.

We determined the total $\mathrm{AN}(\mathcal{N})$ in each eddy using Equation 2. For the summer eddy, since the sampling was opportunistic, $\mathcal{N}$ was computed from two radial transects, bifurcated by the center of the eddy $\left(143.85^{\circ} \mathrm{E}\right.$, $49.68^{\circ} \mathrm{S}$ ) based on altimetry (Figure 1a). For the autumn eddy, $\mathcal{N}$ was computed for three radial transects, one from the northwestern edge of the eddy to the center and two repeat transects from the center of the eddy to its eastern edge (Figure 1b).

The summer eddy carried total available nitrate, silicate, and phosphate content of $11 \pm 8.5 \times 10^{9}$, $-1.1 \pm 1.1 \times 10^{10}$, and $5.3 \pm 3.5 \times 10^{8}$ moles, respectively. The negative $\mathcal{N}$ for silicate indicates that the eddy was depleted relative to the SAZ. The autumn eddy carried total available nitrate, silicate, and phosphate content of $8.7 \pm 0.4 \times 10^{9},-3.0 \pm 0.4 \times 10^{10}$ and $7.3 \pm 2 \times 10^{8}$ moles, respectively. These total available contents were computed as a mean of two transects for the summer eddy and three transects for the autumn eddy. Error estimates are the standard error of the mean $\left(\sigma_{M}=\sigma / \sqrt{n}\right.$, where $\sigma$ is standard deviation and $n$ is number of radial transects). We also note higher error bounds in the summer eddy compared with the autumn eddy. This is due to the asymmetric distribution of nutrients across the summer eddy, giving different estimates of nutrient content from each of the two transects (Figure 9). In the autumn eddy, three transects gave similar estimates of nutrient content. 


\section{Discussion}

We studied two eddies using ship-based observations. Both eddies were generated by frontal instability of the northern branch of the SAF south of Tasmania. One eddy was formed in late austral spring (12 November) and was sampled in midaustral summer (17-18 January, summer eddy); the other was formed in late austral summer ( 3 February) and was sampled in austral autumn (30 March to 5 April, autumn eddy). The former was an opportunistic eddy survey and the latter was a dedicated eddy survey. Given the limited in situ observations of the biogeochemical structure of Southern Ocean eddies, these observations provide insight into the seasonal difference of the biogeochemical structure of cold-core eddies in the Southern Ocean. Analysis of the dynamical properties of the eddies such as rotational speed, diameter, and amplitude, using altimetry and eddy-tracking software (based on methodology described in Patel et al., 2019), indicated that both eddies were sampled during their declining life phase. Eddies have maximum impact on the local system while they dissipate (McGillicuddy Jr, 2016). Therefore, we discuss the results in the context of the eddies' impact on the local system. Furthermore, we also discuss the mechanism that could potentially drive the observed subsurface structure of the eddies.

\subsection{Macronutrient Structure of Southern Ocean Eddies}

Both eddies exhibited intense doming of isopycnal surfaces-quintessential characteristics of cyclonic eddies. For example, the $26.9 \mathrm{~kg} \mathrm{~m}^{-3}$ isopycnal was elevated by 400 dbar from its SAZ depth near 600 dbar at the edges of each eddy, to approximately $200 \mathrm{dbar}$ in the eddy center (Figure 3). However, this doming was inhibited at the base of the mixed layer due to strong surface mixing as evident through the relatively flat $26.6 \mathrm{~kg} \mathrm{~m}^{-3}$ isopycnal (Figure 3).

Below the mixed layer, the nutrients' subsurface structure was similar in both eddies. Furthermore, isopleths of nutrients were aligned with isopycnal surfaces at least up to the limit of the observations-a clear indication of eddy-induced nutrient supply. For the summer eddy, this alignment extended to approximately 3,000 dbar and for the autumn eddy to 1,500 dbar (limit of observations). Kuwahara et al. (2008) proposed that cyclonic eddies around Hawaii modulate nutrients to a depth of at least 300 dbar during their mature phase by comparing their cyclonic eddy with other sampled cyclonic eddies in the region. Given the deep extension of mesoscale eddies (Frenger et al., 2015; Patel et al., 2019; Swart et al., 2008) and the strong coupling between physical and biogeochemical tracers in the Southern Ocean (Demuynck et al., 2019), we propose that Southern Ocean cyclonic eddies have the potential to modulate nutrient fluxes, through eddy pumping, to much greater depths than in other parts of the world ocean.

The Southern Ocean eddies that we observed encapsulated anomalously high-nitrate, high-silicate, and high-phosphate waters in their core, relative to surrounding waters when anomalies were computed in an isobaric coordinate system (Figure 4). However, these anomalous waters were located at different depths. Specifically, the silicate anomaly core was deeper (900-1100 dbar) than that of nitrate and phosphate (300-500 dbar, Figure 4). This discrepancy in the core locations can be attributed to background vertical gradients of nutrients as evident from Figure 3 and the variable impact of phytoplankton species on the silicon cycle in the Southern Ocean (Smetacek et al., 2004). This vertical gradient exists largely due to decoupling of the silicon cycle from the nitrate and phosphate cycle. On average, silicate regeneration occurs at around 2,300 $\mathrm{m}$ and that of phosphate at around $600 \mathrm{~m}$ in the Southern Ocean (Holzer et al., 2014).

In the isopycnal coordinate system, the core of maximum nitrate anomaly was located between 26.8 and 26.9 $\mathrm{kg} \mathrm{m}^{-3}$ for the summer eddy and between 26.6 and $26.7 \mathrm{~kg} \mathrm{~m}^{-3}$ for the autumn eddy (Figure 5). These cores were close to the core of SAMW (Herraiz-Borreguero \& Rintoul, 2010). Below $27 \mathrm{~kg} \mathrm{~m}^{-3}$, at the level of Antarctic Intermediate Water, the nitrate anomalies were close to zero for both eddies (Figure 5). The nitrate distribution across the full extent of the ACC from the WOCE SR03 hydrographic line indicated that nitrate concentration mostly varies in the upper $500 \mathrm{dbar}$ and above the density range of $27 \mathrm{~kg} \mathrm{~m}^{-3}$ (Figure 2). This explains the nitrate-replete core of the eddy compared with surrounding SAZ water properties.

The silicate anomaly distribution in the isopycnal coordinate exhibited a dipole structure for the summer eddy and a monopole structure for the autumn eddy. That is, the silicate anomalies in the summer eddy were positive and that in the autumn eddy were close to zero above the $27 \mathrm{~kg} \mathrm{~m}^{-3}$ isopycnal and negative below that isopycnal for both eddies (Figure 5b). This discrepancy in the silicate anomaly distribution could be attributed to the meridional gradient of silicate uptake or primary productivity, or both (Smetacek et al., 

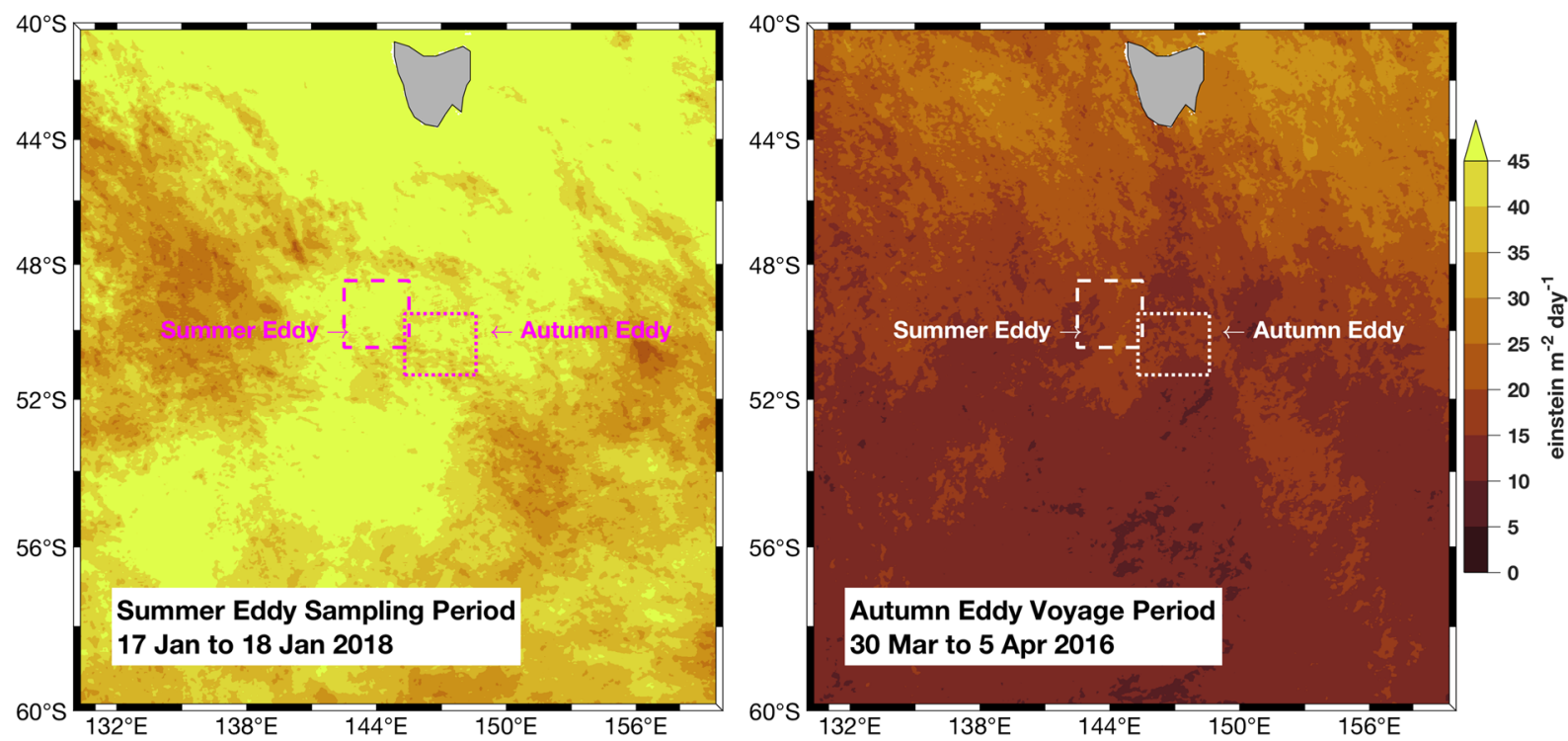

Figure 10. Photosynthetically available radiation during sampling periods.

2004). Overall, the impact of the eddies on the local environment not only depends on the eddy dynamics but also on the background gradient of nutrients within which the eddies are transiting.

\subsection{Biological Structure of Southern Ocean Eddies}

Unlike the nutrients' subsurface structure of the eddies, the biological subsurface structure differed between eddies, especially in terms of biomass and by-product distribution (Figure 6).

Our results indicated that the summer eddy carried two times higher biomass in its core than the autumn eddy, and the majority of biomass was confined in the surface mixed layer (Figure 6). This observation suggested that the seasonal signal of productivity does not penetrate below the surface mixed layer. Since both eddies were formed in the prevailing high-nutrient low-chlorophyll conditions, biomass can be limited by bottom-up (silicate, iron, and light) and top-down (grazing) factors (Boyd et al., 2001; Smetacek et al., 2004). Thus, we next assess these factors to understand why the biomass concentration between the eddies was different.

Satellite observations indicated that during the summer eddy sampling, photosynthetically available radiation (PAR) was two times higher than during the autumn eddy sampling period (Figure 10). Iron is relatively high on the northern side of the ACC and low on the southern side of the ACC as demonstrated by the modeling study of Hense et al. (2003). The summertime iron budget over the south of Tasmania reveals that northern SAZ waters are enriched with iron owing to both seasonal iron supply and wind-blown dust deposition (Bowie et al., 2009). Given that both eddies were formed in the SAF and in different seasons, the summer eddy in mid-November and the autumn eddy in early February (Patel et al., 2019), they had different initial nutrients and phytoplankton stocks at their formation site. This is because nutrient-rich water upwells on the southern side of the ACC and nutrients are consumed rapidly in the spring (spring bloom events) and less rapidly at other times of the year (Deppeler \& Davidson, 2017). Simultaneously, this upwelled water moves north due to Ekman transport. These surface waters are then trapped in cold-core eddies associated with instability of the ACC fronts (Frenger et al., 2018; Spall, 2000) and are carried into the SAZ. In the case of the autumn eddy, iron and silicate could have already been drawn down substantially before the eddy trapped the water from the SAF. Thus, the low biomass concentration in the autumn eddy core could be due to iron limitation or high concentration of zooplankton (Ellwood et al., 2020; Moreau et al., 2017). But for the summer eddy, silicate was still high and iron is believed to be sufficient, during this time of the year, near the SAF (Hense et al., 2003). This could alleviate the nutrient limitation for the biomass that was trapped in the eddy. Together, this could explain the higher biomass concentration in the summer eddy. Thus, not all cyclonic eddies in the Southern Ocean are unproductive. Rather, cyclonic eddies' role in productivity largely depends on its formation site and encapsulation of nutrients as well as phytoplankton. 
In the summer eddy, a subsurface maximum in ammonium $\left(>0.5 \mu \mathrm{mol} \mathrm{L}{ }^{-1}\right)$ was observed across the eddy and around the mixed layer depth (Figure 6c). This is consistent with the rest of the SR03 transect. In the autumn eddy, a subsurface ammonium maximum $\left(>0.7 \mu \mathrm{mol} \mathrm{L}{ }^{-1}\right)$ was only observed at the core just below the mixed layer, which was exhausted of biomass above (Figure 6). This is consistent with the study of Blain et al. (2015) and Fripiat et al. (2015). Both studies reported a subsurface ammonium maximum in the Southern Ocean near the Kerguelen Plateau between 50 and $150 \mathrm{~m}$. The magnitude of the autumn eddy subsurface ammonium maximum $\left(0.7-0.8 \mu \mathrm{mol} \mathrm{L}{ }^{-1}\right)$ was slightly higher than Blain et al. (2015, 0.5$\left.0.6 \mu \mathrm{mol} \mathrm{L}^{-1}\right)$ and lower than Fripiat et al. $\left(2015,1.3-2.3 \mu \mathrm{mol} \mathrm{L}{ }^{-1}\right)$.

The stratification (represented as Brunt-Vaisala frequency of $>0.004 \mathrm{~s}^{-1}$, Figure $6 \mathrm{c}$ ) was stronger in the summer eddy than in the autumn eddy. The stratification was strongest at the mixed layer depth, potentially suspending particulate organic matter and allowing microorganisms to decompose organic matter within the layer. The autumn eddy had strong stratification in the core, but weak stratification around the eddy periphery. This difference in stratification could be due to seasonal variability as stratification is stronger in summer than in autumn (Rintoul \& Trull, 2001). The difference may also be due to processes internal to the eddies. For example, at the eddy center, a cyclonic eddy can generate additional stratification by squeezing isopycnals due to strong mixing in the surface layer and eddy-induced uplift of isopycnals (Figure 3). The eddy-induced stratification at the center of the autumn eddy enhances the otherwise weak stratification relative to the surrounding waters. This feature of cold-core eddies increases the residence time of the sinking particulate organic matter and thus retains ammonium longer than in surrounding waters. This highlights the potentially important role of cold-core eddies in nutrient cycling.

\subsection{Meridional Transport of Nitrate and Silicate}

We quantify the role of long-lived (lifespan $>90$ days) cold-core eddies in the meridional transport of nitrate and silicate using our in situ observations, combining them with an eddy census from satellite altimetry (Faghmous et al., 2015; Patel et al., 2019). To do so, we employ a method commonly used to study the meridional heat and salt transport by Southern Ocean eddies. The application of the method is described in Appendix A1. In our study region $\left(45^{\circ} \mathrm{S}\right.$ to $55^{\circ} \mathrm{S} ; 135^{\circ} \mathrm{E}$ to $\left.155^{\circ} \mathrm{E}\right)$, we found that, on average, all the long-lived cold-core eddies transferred $1.6 \pm 0.2 \times 10^{10}$ moles of nitrate and $-5.5 \pm 0.7 \times 10^{10}$ moles of silicate annually across the SAF into the SAZ.

To assess the relative importance of this meridional transport of nutrients by discrete long-lived cold-core eddies, we compare it with Ekman transport. In the zonally unbounded ACC, meridional transport occurs due to combined contribution of Ekman transport and eddies (Dufour et al., 2015). Ekman transport has been shown in modeling studies to be a pivotal mechanism for meridional transport of physical and biogeochemical properties across the ACC (Dufour et al., 2015; Ito et al., 2010; Palter et al., 2013). We therefore estimate the mass of nutrients that is carried across the SAF in the Ekman layer to compare with our estimate of nutrient transport by cold-core eddies. To do so, we consider a $50 \mathrm{~m}$ deep layer, expanding zonally over $1,400 \mathrm{~km}\left(135^{\circ} \mathrm{E}\right.$ to $\left.155^{\circ} \mathrm{E}\right)$ and extending over $50 \mathrm{~km}$ north of the SAF (as done in Morrow et al., 2004; Patel et al., 2019). This layer holds an anomaly of about $2 \mu \mathrm{mol} \mathrm{L} \mathrm{L}^{-1}$ of nitrate (estimated from Figure 2, $\sim 18 \mu \mathrm{mol} \mathrm{L}{ }^{-1}$ south of the SAF and $\sim 16 \mu \mathrm{mol} \mathrm{L}^{-1}$ in the SAZ). Thus, the Ekman transport would carry about $0.7 \times 10^{10}$ moles of nitrate each year, which is approximately $43 \%$ of the total annual nitrate transport by long-lived cold-core eddies. A similar computation for silicate indicates that Ekman transport would bring about $0.7 \times 10^{10}$ moles annually to the SAZ, which is approximately $13 \%$ of that due to long-lived cold-core eddies but of opposite sign. Therefore, Ekman transport would slightly compensate the silicate deficit transport by eddies to the SAZ.

The other possible mechanisms for nutrient transport across the SAF include anticyclonic (warm-core) eddies moving waters towards the Polar Frontal Zone, short-lived eddies both cyclonic and anticyclonic, baroclinic instability pumping water laterally more or less along isopycnals, and smaller-scale processes that are not resolved by our observations. The importance of decaying cold-core eddies should be compared with some estimate of the transport of nutrients by all of these processes combined. This is a goal beyond the limit of our observations and will be addressed in ongoing model evaluation for a future study. 


\subsubsection{Modification of SAMW Properties}

SAMW is an important conduit for the subduction and export of nutrients out of the Southern Ocean. Macronutrient concentrations in the formation zone of SAMW can be large, due to iron limitation in the Southern Ocean (Moore et al., 2013). This export constitutes the preformed component of the SAMW nutrient content, which is then added by remineralization as the mode waters traverse northward. Indeed, it has been estimated that mode water nutrients are responsible for up 33\% to 75\% of the global ocean export production north of $30^{\circ} \mathrm{S}$ (Palter et al., 2010). SAMW forms due to strong convection during winter, forming a deep winter mixed layer in the SAZ. Our study region, the SAZ south of Tasmania, is a place where large amounts of SAMW form (Herraiz-Borreguero \& Rintoul, 2010). SAMW is identified by its uniform density characteristics and is generally defined as having potential density in the range 26.5 to $27.0 \mathrm{~kg} \mathrm{~m}^{-3}$ (Hanawa \& Talley, 2001). Furthermore, SAMW properties such as low potential vorticity and low $\mathrm{Si}^{*}$ (silicate - nitrate) can be useful water mass tracers to follow SAMW through the oceans (Hanawa \& Talley, 2001; Sarmiento et al., 2004).

We exploit the quasi-conservative property of the SAMW, $\mathrm{Si}^{*}$, to understand how this meridional transport of nitrate and silicate might impact the nutrient properties of SAMW. To accomplish this, we first obtained a representative $\mathrm{Si}^{*}$ value for $\mathrm{SAMW}$ in the region of interest $\left(46^{\circ} \mathrm{S}\right.$ to $50^{\circ} \mathrm{S}$ and $135^{\circ} \mathrm{E}$ to $155^{\circ} \mathrm{E}, 26.5$ to $27.0 \mathrm{~kg} \mathrm{~m}^{-3}$ ). Our estimate of $\mathrm{Si}^{*}$ from the CARS climatology $\left(-10.32 \pm 2.02 \mu \mathrm{mol} \mathrm{L}^{-1}\right)$ and SR03 stations $\left(-11.70 \pm 1.83 \mu \mathrm{mol} \mathrm{L} \mathrm{L}^{-1}\right)$, sampled between $46^{\circ}-50^{\circ} \mathrm{S}$, is consistent with the reported range of -10 to $-15 \mu \mathrm{mol} \mathrm{L}{ }^{-1}$ in Sarmiento et al. (2004). Thus, the average $\mathrm{Si}^{*}$ of the SAZ would be approximately $-11.38 \mu \mathrm{mol} \mathrm{L}{ }^{-1}$-a mean of the above estimates.

We compared the background SAZ Si* to the $\mathrm{Si}^{*}$ for both the summer $\left(-13.02 \pm 1.01 \mu \mathrm{mol} \mathrm{L}{ }^{-1}\right)$ and the autumn $\left(-14.50 \pm 3.20 \mu \mathrm{mol} \mathrm{L}{ }^{-1}\right)$ eddies. Both of these $\mathrm{Si}^{*}$ estimates were still in the range of typical SAMW $\mathrm{Si}^{*}$ values. However, eddies appear to carry between $14 \%$ and $27 \%$ more negative $\mathrm{Si}^{*}$ than a representative $\mathrm{Si}^{*}$ of the $\mathrm{SAZ}$ box. In other words, eddies can drive SAMW towards stronger $\mathrm{Si}^{*}$ depletion, by adding either low-silicate water or high-nitrate water that was trapped at their origin. Therefore, the scaling argument indicates that eddies can potentially modify SAMW nutrient concentration; however, it does not illustrate how.

We next explore how eddies modify SAMW properties by calculating the total ANs carried in the density range of SAMW by the cold-core eddies (Table A1). Our result indicates that the long-lived cold-core eddies increase SAMW nitrate content by adding $2 \pm 0.2 \times 10^{10}$ moles annually and deplete SAMW silicate content by removing $-0.7 \pm 0.1 \times 10^{10}$ moles annually. This suggests that the long-lived cold-core eddies carry about $25 \%$ higher nitrate content in the SAMW density range than is carried over the full density range of the eddy $\left(1.6 \pm 0.2 \times 10^{10}\right.$ moles). Likewise, the long-lived cold-core eddies carry about $87 \%$ lower silicate content in the SAMW density range than is carried over the full density range $\left(-5.5 \pm 0.7 \times 10^{10}\right.$ moles $)$, relative to the SAZ background concentrations. Therefore, this confirms that eddies push SAMW nutrient concentration towards stronger $\mathrm{Si}^{*}$ depletion by adding high-nitrate and low-silicate water in to their formation region. These results further emphasize the fact that mesoscale eddies have the potential to substantially modify SAMW nutrient content.

\subsubsection{Implication for SAZ Productivity}

To understand the impact of eddy nutrient transport into the SAZ, we quantify the role of long-lived cyclonic eddies on the SAZ productivity. For this, we used vertically generalized production model outputs (VGPM, Behrenfeld \& Falkowski, 1997). We first computed monthly primary production over the SAZ box (135 ${ }^{\circ}$ $155^{\circ} \mathrm{E} ; 46^{\circ}-50^{\circ} \mathrm{S}$ ) for 16 years (2003-2018) and examined the annual cycle over the SAZ (Figure 11). Our estimate from VGPM indicated daily primary production of $\sim 620 \mathrm{mg} \mathrm{C} \mathrm{m}^{-2} \mathrm{~d}^{-1}$ in midsummer, average of January and February primary production, which is in good agreement with the measurements of Westwood et al. (2011).

Integrating the area under the annual cycle curve yielded total annual average net primary production of $114.04 \pm 2.24 \mathrm{~g} \mathrm{C} \mathrm{m}^{-2}$ in SAZ waters, where the error is a standard error of the mean. Given the area of $6617.3 \times 10^{8} \mathrm{~m}^{2}$, the total annual production over the SAZ box is $75.5 \pm 1.5 \mathrm{Tg} \mathrm{C} \mathrm{y}^{-1}$.

The long-lived cold-core eddies carried $1.6 \pm 0.2 \times 10^{10}$ moles of nitrate per year into the SAZ from south of the SAF. Given an approximate $f$ ratio, defined as the total primary production that could occurred due to 


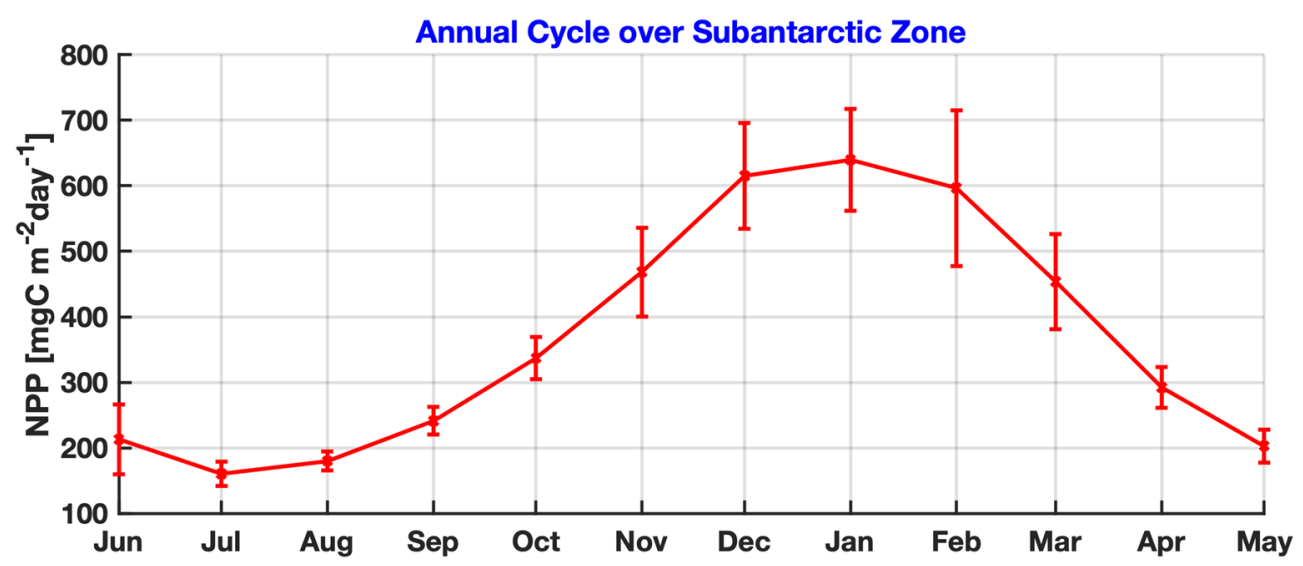

Figure 11. Mean annual cycle of satellite-derived net primary productivity over the Subantactic Zone $\left(135^{\circ}-155^{\circ} \mathrm{E}\right.$ and $46^{\circ}-50^{\circ} \mathrm{S}$ ), calculated from the vertically generalized production model (VGPM, Behrenfeld \& Falkowski, 1997).

nitrate, of 0.2 (based on our observations of deep and surface nitrate), about $20 \%$ of the observed primary productivity is fueled by nitrate. Therefore, we can estimate primary production due to transported nitrate as $20 \%$ of $1.6 \pm 0.2 \times 10^{10}$ moles of nitrate per year in the SAZ. We can convert this to carbon uptake using a Redfield ratio of 6.6 for carbon to nitrate mole ratio for the SAZ (Lourey \& Trull, 2001). Therefore, estimated local primary production due to mesoscale eddies in the SAZ would be $0.25 \pm 0.03 \mathrm{Tg} \mathrm{C}^{-1}$, which is in fact negligible compared with the annual production in the SAZ $\left(75.5 \pm 1.5 \mathrm{Tg} \mathrm{C}^{-1}\right)$. This result is further supported by the fact that productivity in the SAZ south of Tasmania largely depends on iron availability (Boyd et al., 2001; Ellwood et al., 2020). Thus, the majority of nutrients are exported to lower latitudes through subduction and export of SAMW and may support productivity at lower latitudes on longer time scale (Palter et al., 2010; Sarmiento et al., 2004).

We have presented, to our knowledge, the first observation-based estimate of meridional transport of nutrients by discrete mesoscale eddies across the SAF into the SAZ south of Tasmania. This estimate, based on in situ observation of an individual eddy, can further be strengthened by combining altimetry tracked eddies with subsurface measurements from biogeochemical-Argo floats as those observations expand in coverage. Nonetheless, this first estimate of meridional transport of nutrients is useful to assess the impact of mesoscale eddies on SAZ water masses, such as SAMW, which subsequently transports nutrients to low-latitude upwelling regions. Furthermore, it also emphasizes that mesoscale eddies increase nitrate content and decrease silicate content in the SAMW in our study region. This nitrate enrichment of the SAMW will be advantageous for regions where productivity is limited by nitrate. But the silicate depletion of the SAMW will suppress the productivity of diatoms when mode waters are exported to lower latitudes.

\section{Conclusion}

In situ observations from two voyages were used to understand the role of eddies in the regional biology and biogeochemistry of Southern Ocean waters south of Tasmania. Our aim was to illustrate the vertical biogeochemical structure of Southern Ocean eddies, quantify their contribution to the cross-frontal transport of nutrients, and assess their impact on regional productivity and mode water modification. Our results indicated strong coupling between physical and biogeochemical properties. Such coupling drives nutrient distribution across the eddies resulting in no seasonal variation in nutrient distribution below the mixed layer. We found that long-lived cold-core eddies carried anomalously high-nitrate $\left(1.6 \pm 0.2 \times 10^{10}\right.$ moles per year $)$ and anomalously low-silicate $\left(-5.5 \pm 0.7 \times 10^{10}\right.$ moles per year) waters across the SAF into the SAZ. This deficit of silicate delivered to the SAZ by long-lived cold-core eddies is partially compensated by the northward Ekman transport of waters with relatively high silicate content. We found that the estimated meridional transport by long-lived cold-core eddies has negligible impact on the SAZ productivity. This is consistent with previous studies, as productivity in the Southern Ocean is largely driven by availability of iron. However, we found that long-lived cold-core eddies modify mode water nutrient contents by delivering 
water with $14 \%$ to $27 \%$ more negative $\mathrm{Si}^{*}$ value than typical values for the mode water in the SAZ. This has implications for global productivity and hence carbon export.

\section{Appendix A: Relationship Between Sea Surface Height and Subsurface Nutrient Structure}

The high correlation between sea surface height and subsurface temperature and salinity distribution has been exploited to study the meridional transport of heat and salt by eddies in the Southern Ocean (Patel et al., 2019; Swart et al., 2008). The reason this method is possible is because the strongly sloping isopycnals in the Southern Ocean are dynamically linked to the water mass structure below the sea surface. In a way, the position across the ACC is uniquely determined by sea surface height, estimated either from the calculation of dynamic height from the in situ profile or from altimeter measurements of sea surface height. The dynamic height of a profile then provides a coordinate frame that follows the north-south movements of ACC fronts (and eddies). Dynamic height as a meridional coordinate has been used to construct time-varying climatologies of temperature and salinity for the Southern Ocean that more realistically capture the Southern Ocean's dynamic frontal systems than averaging in latitude bins (Meijers et al., 2011; Sun \& Watts, 2001; Swart et al., 2010).

Our measurements reveal a significant correlation between the vertical structure of nutrients and dynamic height, calculated from our in situ measurement with respect to 1,500 dbar (Figure A1). The correlation is especially high between $\sim 150$ and 1,100 dbar, confirming that modulation in sea surface height (position across the ACC) is reflected in the subsurface nutrient structure (Figure A1). The correlation above $150 \mathrm{dbar}$ could be improved by removing the seasonal cycle of nutrients in the mixed layer as is often done for GEM (Meijers et al., 2011; Watts et al., 2001). Thus, we can extract substantial information on the subsurface structure of nutrients in the Southern Ocean purely based on surface proxies such as dynamic height (Figure A1) or integrated surface elevation of eddies.

We adapt the method used to track the heat and salt content of eddies (e.g., Patel et al., 2019) to quantify the amount of nutrients carried by long-lived (lifespan $>90$ days) cold-core eddies in our region over the 22-year altimeter record. The approach is as follows:

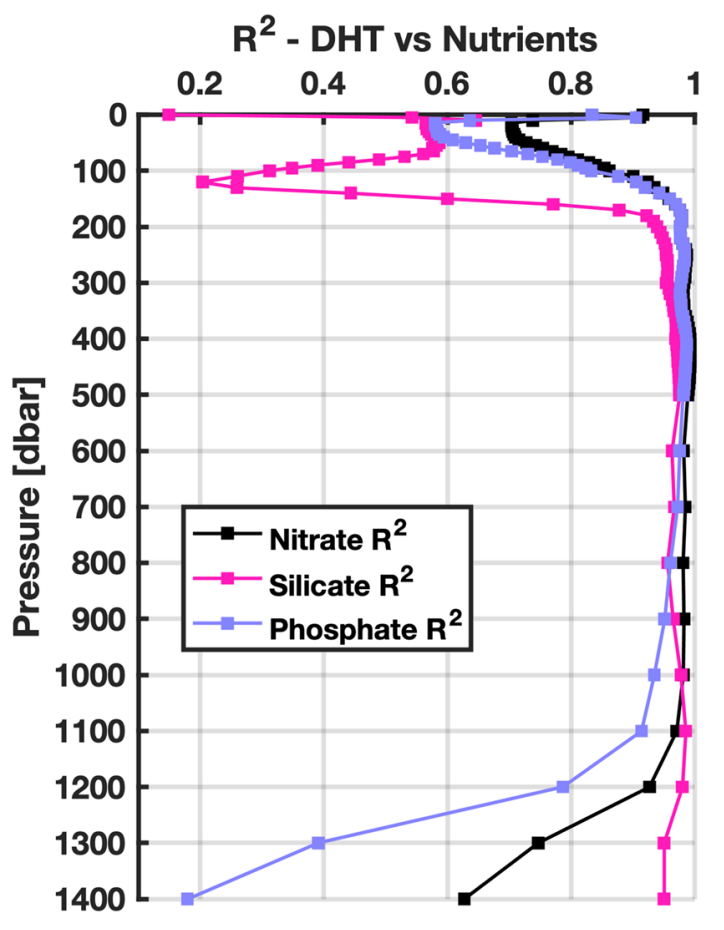

Figure A1. Relationship between nutrients and dynamic height when a quadratic equation is fitted at each pressure levels denoted as squares.
1. From a shipboard survey of the subsurface structure of an eddy, compute the total available nutrient content carried by that eddy (as demonstrated in sections 2.4 and 2.5.).

2. From satellite altimeter data during the voyage, compute the approximate volume of the sampled eddy, quantified by its integrated surface elevation (ISE). The ISE $(=1 / 3 \times$ amplitude $\times$ surface area) approximates the volume of the eddy that is elevated above the zero sea-level anomaly contour (Patel et al., 2019; Swart et al., 2008).

3. Derive an empirical relationship between the total available nutrient content of the observed eddy and its ISE during sampling.

4. Determine the ISE of all eddies that have occupied the target region over the altimeter record.

5. Use the empirical relationship to infer the nutrient content of eddies from their ISE for each day of their lifetime.

For the autumn eddy, total available nutrient content $(\mathscr{N})$ measured during sampling was $8.7 \pm 0.4 \times 10^{9}$ moles for nitrate and $-3.0 \pm 0.4 \times 10^{10}$ moles for silicate. The average ISE of the autumn eddy over the sampling period was $4.72 \times 10^{9} \mathrm{~m}^{3}$. Thus, the empirical relationship between total available nitrate and silicate carried by the autumn eddy and its ISE is

$$
\mathcal{N}_{N}=1.84 \cdot \operatorname{ISE}(\text { moles }) ; \quad \mathcal{N}_{S i}=-6.38 \cdot \operatorname{ISE}(\text { moles })
$$

where $\mathcal{N}_{N}$ and $\mathcal{N}_{S i}$ are total available nitrate and silicate, respectively.

We apply the relationship (Equation A1) to the 22-year (1993-2014) history of eddies formed at the $\mathrm{SAF}$ in the $20^{\circ}$ longitude range $\left(135^{\circ} \mathrm{E}\right.$ to 
Table A1

Total Nutrient Transport in the Subantarctic Zone by the Eddies That Dissipated in the Subantarctic Zone and Subantarctic Front Over 22 years in the $20^{\circ}$ Longitude Range, Calculated Over the Full Density Range ( $\sigma_{\theta}=26.5$ to 27.5) and Mode Water Density Range $\left(\sigma_{\theta}=26.5\right.$ to 27.0)

\begin{tabular}{|c|c|c|c|c|c|}
\hline \multirow[b]{2}{*}{ Eddy pathway } & \multirow[b]{2}{*}{ No. of eddies } & \multicolumn{2}{|c|}{ Full density range } & \multicolumn{2}{|c|}{ SAMW density range } \\
\hline & & $\mathcal{N}_{N}($ moles $)$ & $\mathscr{N}_{S i}($ moles $)$ & $\mathcal{N}_{N}($ moles $)$ & $\mathcal{N}_{S i}($ moles $)$ \\
\hline Dissipating frontal eddy & 29 & $2.2 \times 10^{11}$ & $-7.5 \times 10^{11}$ & $2.7 \times 10^{11}$ & $-1.0 \times 10^{11}$ \\
\hline Return frontal eddy & 14 & $1.3 \times 10^{11}$ & $-4.7 \times 10^{11}$ & $1.7 \times 10^{11}$ & $-0.6 \times 10^{11}$ \\
\hline Frontal mixing eddy & 15 & 0 & 0 & 0 & 0 \\
\hline Total transport & & $3.5 \times 10^{11}$ & $-12.2 \times 10^{11}$ & $4.4 \times 10^{11}$ & $-1.6 \times 10^{11}$ \\
\hline
\end{tabular}

\section{Acknowledgments}

This study is a part of the EDDY project: http://southernoceaneddie.wixsite. com/eddies. This research is supported by an Australian Research Council Discovery Project (DP160102870), the Australian Research Council's Special Research Initiative for Antarctic Gateway Partnership (SR140300001), and ship time from Australia's Marine National Facility (MNF). We thank the officers, crew, and technical staff of Australia's MNF R.V. Investigator for their assistance during data collection from both voyages. R. Patel thanks Quantitative Marine Science PhD program for providing financial support to conduct his research. R. Patel also thanks Kimberlee Baldry for thoughtful insights into chlorophyll quenching correction. HP acknowledges funding from the Australian Government's National Environmental Science Program. We thank two anonymous reviewers whose constructive comments greatly improved this manuscript. $155^{\circ} \mathrm{E}$ ), which surrounds our in situ observations. These eddies were identified in the eddy tracking data set from Patel et al. (2019) and include only eddies that were formed in the SAF. These eddies were divided into three categories based on the pathways that they followed after formation: dissipating frontal eddies, return frontal eddies, and frontal mixing eddies (Patel et al., 2019). These pathways are critical for the meridional transport estimation as explained here. Dissipating frontal eddies never return to the SAF and therefore contribute all their transported nutrients to the SAZ. Return frontal eddies return to the SAF after transiting into the SAZ and only contribute a fraction of nutrients into the SAZ (the difference between the nutrient content at dissipation and their maximum nutrient content). Frontal mixing eddies never leave the SAF, so they do not contribute to meridional transport.

Out of 63 long-lived (>90 days) cyclonic eddies, $46 \%$ of eddies were characterized as dissipating frontal eddies, $22 \%$ of eddies were characterized as return frontal eddies, $24 \%$ of eddies were characterized as frontal mixing eddies, and the fate of 5\% was unknown (Patel et al., 2019). The contribution of the eddies to the meridional transport of nitrate and silicate over the full density range is tabulated for our region of interest over the period of 22 years (Table 1). This allowed us to quantify the impact of the long-lived mesoscale cyclonic eddies on the meridional transport of nitrate and silicate through either enrichment or depletion of the SAZ water properties.

\section{Data Availability Statement}

The observations used in this study can be obtained from the authors and MNF website (https://www.cmar. csiro.au/data/trawler/).

\section{References}

Ardyna, M., Claustre, H., Sallée, J.-B., d'Ovidio, F., Gentili, B., Van Dijken, G., et al. (2017). Delineating environmental control of phytoplankton biomass and phenology in the Southern Ocean. Geophysical Research Letters, 44, 5016-5024. https://doi.org/10.1002/ 2016GL072428

Armstrong, F. A. J., Stearns, C. R., \& Strickland, J. D. H. (1967). The measurement of upwelling and subsequent biological process by means of the technicon autoanalyzer ${ }^{\circledast}$ and associated equipment. Deep Sea Research and Oceanographic Abstracts, 14(3), 381-389.

Arrigo, K. R. (2005). Marine microorganisms and global nutrient cycles. Nature, 437(7057), 349-355.

Arrigo, K. R., Robinson, D. H., Worthen, D. L., Dunbar, R. B., DiTullio, G. R., VanWoert, M., \& Lizotte, M. P. (1999). Phytoplankton community structure and the drawdown of nutrients and CO2 in the Southern Ocean. Science, 283(5400), 365-367.

Behrenfeld, M. J., \& Falkowski, P. G. (1997). Photosynthetic rates derived from satellite-based chlorophyll concentration. Limnology and oceanography, 42(1), 1-20.

Blain, S., Capparos, J., Guéneuguès, A., Obernosterer, I., \& Oriol, L. (2015). Distributions and stoichiometry of dissolved nitrogen and phosphorus in the iron-fertilized region near Kerguelen (Southern Ocean). Biogeosciences, 12(2), 623-635.

Bowie, A. R., Lannuzel, D., Remenyi, T. A., Wagener, T., Lam, P. J., Boyd, P. W., et al. (2009). Biogeochemical iron budgets of the Southern Ocean south of Australia: Decoupling of iron and nutrient cycles in the Subantarctic Zone by the summertime supply. Global Biogeochemical Cycles, 23, GB4034. https://doi.org/10.1029/2009GB003500

Boyd, P. W., Crossley, A. C., DiTullio, G. R., Griffiths, F. B., Hutchins, D. A., Queguiner, B., et al. (2001). Control of phytoplankton growth by iron supply and irradiance in the subantarctic Southern Ocean: Experimental results from the SAZ project. Journal of Geophysical Research: Oceans, 106(C12), 31,573-31,583.

Briggs, N., Perry, M. J., Cetinić, I., Lee, C., D'Asaro, E., Gray, A. M., \& Rehm, E. (2011). High-resolution observations of aggregate flux during a sub-polar north atlantic spring bloom. Deep Sea Research Part I: Oceanographic Research Papers, 58(10), 1031-1039.

Chenillat, F., Franks, P. J. S., \& Combes, V. (2016). Biogeochemical properties of eddies in the california current system. Geophysical Research Letters, 43, 5812-5820. https://doi.org/10.1002/2016GL068945

Coale, K. H., Johnson, K. S., Chavez, F. P., Buesseler, K. O., Barber, R. T., Brzezinski, M. A., et al. (2004). Southern Ocean iron enrichment experiment: Carbon cycling in high-and low-si waters. Science, 304(5669), 408-414.

Dehairs, F., Fripiat, F., Cavagna, A.-J., Trull, T. W., Fernandez, C., Davies, D., et al. (2015). Nitrogen cycling in the Southern Ocean Kerguelen plateau area: Evidence for significant surface nitrification from nitrate isotopic compositions. Biogeosciences, 12, 1459-1482. 
Demuynck, P., Tyrrell, T., Naveira Garabato, A., Moore, M. C., \& Martin, A. P. (2019). Spatial variations in silicate-to-nitrate ratios in the Southern Ocean surface waters are controlled in the short term by physics rather than biology. Biogeosciences Discussions, $2019,1-33$. https://doi.org/10.5194/bg-2019-120

Deppeler, S. L., \& Davidson, A. T. (2017). Southern Ocean phytoplankton in a changing climate. Frontiers in Marine Science, $4,40$.

Dufour, C. O., Griffies, S. M., de Souza, G. F., Frenger, I., Morrison, A. K., Palter, J. B., et al. (2015). Role of mesoscale eddies in cross-frontal transport of heat and biogeochemical tracers in the Southern Ocean. Journal of Physical Oceanography, 45(12), $3057-3081$.

Ellwood, M. J., Strzepek, R. F., Strutton, P. G., Trull, T. W., Fourquez, M., \& Boyd, P. W. (2020). Distinct iron cycling in a Southern Ocean eddy. Nature Communications, 11(1), 1-8.

Faghmous, J. H., Frenger, I., Yao, Y., Warmka, R., Lindell, A., \& Kumar, V. (2015). A daily global mesoscale ocean eddy dataset from satellite altimetry. Scientific data, 2(1), 1-16.

Falkowski, P. G., Ziemann, D., Kolber, Z., \& Bienfang, P. K. (1991). Role of eddy pumping in enhancing primary production in the ocean. Nature, 352(6330), 55 .

Frenger, I., Münnich, M., \& Gruber, N. (2018). Imprint of Southern Ocean eddies on chlorophyll. Biogeosciences (BG), 15, 4781-4798.

Frenger, I., Münnich, M., Gruber, N., \& Knutti, R. (2015). Southern Ocean eddy phenomenology. Journal of Geophysical Research: Oceans, 120, 7413-7449. https://doi.org/10.1002/2015JC011047

Fripiat, F., Elskens, M., Trull, T. W., Blain, S., Cavagna, A.-J., Fernandez, C., et al. (2015). Significant mixed layer nitrification in a natural iron-fertilized bloom of the Southern Ocean. Global Biogeochemical Cycles, 29, 1929-1943. https://doi.org/10.1002/2014GB005051

Grenier, M., Della Penna, A., \& Trull, T. W. (2015). Autonomous profiling float observations of the high-biomass plume downstream of the Kerguelen plateau in the Southern Ocean. Biogeosciences, 12(9), 2707-2735.

Gruber, N., Lachkar, Z., Frenzel, H., Marchesiello, P., Münnich, M., McWilliams, J. C., et al. (2011). Eddy-induced reduction of biological production in eastern boundary upwelling systems. Nature Geoscience, 4(11), 787

Hanawa, K., \& Talley, L. D. (2001). Mode waters. In G. Siedler et al. (Eds.), Ocean circulation and climate: Observing and modelling the global ocean, International Geophysics Series (Vol. 77, pp. 373-386).

Hauck, J., Lenton, A., Langlais, C., \& Matear, R. (2018). The fate of carbon and nutrients exported out of the Southern Ocean. Global Biogeochemical Cycles, 32, 1556-1573. https://doi.org/10.1029/2018GB005977

Hense, I., Timmermann, R., Beckmann, A., \& Bathmann, U. V. (2003). Regional ecosystem dynamics in the ACC: Simulations with a three-dimensional ocean-plankton model. Journal of Marine Systems, 42(1-2), 31-51.

Herraiz-Borreguero, L., \& Rintoul, S. R. (2010). Subantarctic mode water variability influenced by mesoscale eddies south of Tasmania. Journal of Geophysical Research, 115, C04004. https://doi.org/10.1029/2008JC005146

Holzer, M., Primeau, F. W., DeVries, T., \& Matear, R. (2014). The Southern Ocean silicon trap: Data-constrained estimates of regenerated silicic acid, trapping efficiencies, and global transport paths. Journal of Geophysical Research: Oceans, 119, 313-331. https://doi.org/ 10.1002/2013JC009356

Hutchins, D. A., Sedwick, P. N., DiTullio, G. R., Boyd, P. W., Queguiner, B., Griffiths, F. B., \& Crossley, C. (2001). Control of phytoplankton growth by iron and silicic acid availability in the subantarctic Southern Ocean: Experimental results from the saz project. Journal of Geophysical Research, 106(C12), 31,559-31,572.

Ito, T., Woloszyn, M., \& Mazloff, M. (2010). Anthropogenic carbon dioxide transport in the Southern Ocean driven by Ekman flow. Nature, 463(7277), 80-83.

Joyce, T. M., Patterson, S. L., \& Millard, R. C. (1981). Anatomy of a cyclonic ring in the Drake Passage. Deep Sea Research Part A. Oceanographic Research Papers, 28(11), 1265-1287.

Kahru, M., Mitchell, B. G., Gille, S. T., Hewes, C. D., \& Holm-Hansen, O. (2007). Eddies enhance biological production in the Weddell-Scotia Confluence of the Southern Ocean. Geophysical Research Letters, 34, L14603. https://doi.org/10.1029/2007GL030430

Kuwahara, V. S., Nencioli, F., Dickey, T. D., Rii, Y. M., \& Bidigare, R. R. (2008). Physical dynamics and biological implications of cyclone noah in the lee of Hawai'i during e-flux i. Deep Sea Research Part II: Topical Studies in Oceanography, 55(10-13), 1231-1251.

Ladd, C., Mordy, C. W., Kachel, N. B., \& Stabeno, P. J. (2007). Northern Gulf of Alaska eddies and associated anomalies. Deep Sea Research Part I: Oceanographic Research Papers, 54(4), 487-509.

Lourey, M. J., \& Trull, T. W. (2001). Seasonal nutrient depletion and carbon export in the Subantarctic and Polar Frontal zones of the Southern Ocean south of Australia. Journal of Geophysical Research, 106(C12), 31,463-31,487.

Martiny, A. C., Pham, C. T. A., Primeau, F. W., Vrugt, J. A., Moore, J. K., Levin, S. A., \& Lomas, M. W. (2013). Strong latitudinal patterns in the elemental ratios of marine plankton and organic matter. Nature Geoscience, 6(4), 279-283.

McDougall, T. J., \& Barker, P. M. (2011). Getting started with TEOS-10 and the Gibbs seawater (gsw) oceanographic toolbox. SCOR/IAPSO $W G, 127,1-28$

McGillicuddy Jr, D. J. (2016). Mechanisms of physical-biological-biogeochemical interaction at the oceanic mesoscale. Annual Review of Marine Science, 8, 125-159.

Meijers, A. J. S., Bindoff, N. L., \& Rintoul, S. R. (2011). Estimating the four-dimensional structure of the Southern Ocean using satellite altimetry. Journal of Atmospheric and Oceanic Technology, 28(4), 548-568.

Moore, C. M., Mills, M. M., Arrigo, K. R., Berman-Frank, I., Bopp, L., Boyd, P. W., et al. (2013). Processes and patterns of oceanic nutrient limitation. Nature Geoscience, 6(9), 701-710.

Moreau, S., Penna, A. D., Llort, J., Patel, R., Langlais, C., Boyd, P. W., et al. (2017). Eddy-induced carbon transport across the antarctic circumpolar current. Global Biogeochemical Cycles, 31, 1368-1386. https://doi.org/10.1002/2017GB005669

Morrow, R., Donguy, J.-R., Chaigneau, A., \& Rintoul, S. R. (2004). Cold-core anomalies at the subantarctic front, south of Tasmania. Deep Sea Research Part I: Oceanographic Research Papers, 51(11), 1417-1440.

Nencioli, F., Kuwahara, V. S., Dickey, T. D., Rii, Y. M., \& Bidigare, R. R. (2008). Physical dynamics and biological implications of a mesoscale eddy in the lee of Hawai'i: Cyclone opal observations during e-flux iii. Deep Sea Research Part II: Topical Studies in Oceanography, 55(10-13), 1252-1274.

Palter, J. B., Marinov, I., Sarmiento, J. L., \& Gruber, N. (2013). Large-scale, persistent nutrient fronts of the world ocean: Impacts on biogeochemistry, The Handbook of Environmental Chemistry. Berlin, Heidelberg: Springer.

Palter, J. B., Sarmiento, J. L., Gnanadesikan, A., Simeon, J., \& Slater, R. D. (2010). Fueling export production: Nutrient return pathways from the deep ocean and their dependence on the meridional overturning circulation. Biogeosciences, 7(11), 3549-3568.

Patel, R. S., Phillips, H. E., Strutton, P. G., Lenton, A., \& Llort, J. (2019). Meridional heat and salt transport across the subantarctic front by cold-core eddies. Journal of Geophysical Research: Oceans, 124, 981-1004. https://doi.org/10.1029/2018JC014655

Pollard, R. T., Lucas, M. I., \& Read, J. F. (2002). Physical controls on biogeochemical zonation in the Southern Ocean. Deep Sea Research Part II: Topical Studies in Oceanography, 49(16), 3289-3305. 
Pollard, R., Tréguer, P., \& Read, J. (2006). Quantifying nutrient supply to the Southern Ocean. Journal of Geophysical Research, 111 , C05011. https://doi.org/10.1029/2005JC003076

Rintoul, S. R. (2018). The global influence of localized dynamics in the Southern Ocean. Nature, 558(7709), 209.

Rintoul, S. R., \& Trull, T. W. (2001). Seasonal evolution of the mixed layer in the Subantarctic Zone south of Australia. Journal of Geophysical Research, 106(C12), 31,447-31,462

Sackmann, B. S., Perry, M. J., \& Eriksen, C. C. (2008). Seaglider observations of variability in daytime fluorescence quenching of chlorophyll-a in northeastern pacific coastal waters. Biogeosciences Discussions, 5(4), 2839-2865.

Sarmiento, J. L., Gruber, N., Brzezinski, M. A., \& Dunne, J. P. (2004). High-latitude controls of thermocline nutrients and low latitude biological productivity. Nature, 427(6969), 56.

Siegel, D. A., Peterson, P., McGillicuddy Jr, D. J., Maritorena, S., \& Nelson, N. B. (2011). Bio-optical footprints created by mesoscale eddies in the Sargasso Sea. Geophysical Research Letters, 38, L13608. https://doi.org/10.1029/2011GL047660

Smetacek, V., Assmy, P., \& Henjes, J. (2004). The role of grazing in structuring Southern Ocean pelagic ecosystems and biogeochemical cycles. Antarctic Science, 16(4), 541-558.

Sokolov, S., \& Rintoul, S. R. (2009). Circumpolar structure and distribution of the antarctic circumpolar current fronts: 1 . Mean circumpolar paths. Journal of Geophysical Research, 114, C11018. https://doi.org/10.1029/2008JC005108

Spall, M. A. (2000). Generation of strong mesoscale eddies by weak ocean gyres. Journal of Marine Research, 58(1), 97-116.

Strutton, P. G., Martz, T. R., DeGrandpre, M. D., McGillis, W. R., Drennan, W. M., \& Boss, E. (2011). Bio-optical observations of the 2004 labrador sea phytoplankton bloom. Journal of Geophysical Research, 116, C11037. https://doi.org/10.1029/2010JC006872

Sun, C., \& Watts, D. R. (2001). A circumpolar gravest empirical mode for the Southern Ocean hydrography. Journal of Geophysical Research, 106(C2), 2833-2855.

Swart, N. C., Ansorge, I. J., \& Lutjeharms, J. R. E. (2008). Detailed characterization of a cold antarctic eddy. Journal of Geophysical Research, 113, C01009. https://doi.org/10.1029/2007JC004190

Swart, S., Speich, S., Ansorge, I. J., \& Lutjeharms, J. R. E. (2010). An altimetry-based gravest empirical mode south of africa: 1. Development and validation. Journal of Geophysical Research, 115, C03002. https://doi.org/10.1029/2009JC005299

Takeda, S. (1998). Influence of iron availability on nutrient consumption ratio of diatoms in oceanic waters. Nature, 393(6687), $774-777$.

Wang, G., Zhou, W., Cao, W., Yin, J., Yang, Y., Sun, Z., et al. (2011). Variation of particulate organic carbon and its relationship with bio-optical properties during a phytoplankton bloom in the pearl river estuary. Marine Pollution Bulletin, 62(9), $1939-1947$.

Watts, D. R., Sun, C., \& Rintoul, S. (2001). A two-dimensional gravest empirical mode determined from hydrographic observations in the Subantarctic Front. Journal of Physical Oceanography, 31(8), 2186-2209.

Westwood, K. J., Griffiths, F. B., Webb, J. P., \& Wright, S. W. (2011). Primary production in the Sub-Antarctic and Polar Frontal zones south of Tasmania, Australia; SAZ-Sense survey, 2007. Deep Sea Research Part II: Topical Studies in Oceanography, 58(21-22), 2162-2178.

Wheeler, P. A., \& Kokkinakis, S. A. (1990). Ammonium recycling limits nitrate use in the oceanic subarctic Pacific. Limnology and Oceanography, 35(6), 1267-1278.

Wood, E. D., Armstrong, F. A. J., \& Richards, F. A. (1967). Determination of nitrate in sea water by cadmium-copper reduction to nitrite. Journal of the Marine Biological Association of the United Kingdom, 47(1), 23-31. 